\title{
Elucidating the Chemisorption Phenomena in SERS Studies via Computational Modeling
}

\author{
Yvonne E. Ejorh, William H. Ilsley, Beng Guat Ooi* \\ Department of Chemistry, Middle Tennessee State University, Murfreesboro, TN, USA \\ Email: ^Beng.Ooi@mtsu.edu
}

How to cite this paper: Ejorh, Y.E., Ilsley, W.H. and Ooi, B.G. (2018) Elucidating the Chemisorption Phenomena in SERS Studies via Computational Modeling. Optics and Photonics Journal, 8, 212-234. https://doi.org/10.4236/opj.2018.86019

Received: March 2, 2018

Accepted: June 24, 2018

Published: June 27, 2018

Copyright $\odot 2018$ by authors and Scientific Research Publishing Inc. This work is licensed under the Creative Commons Attribution International License (CC BY 4.0).

http://creativecommons.org/licenses/by/4.0/

(c) (i) Open Access

\begin{abstract}
Colloidal gold solutions with nanostars and nanospheres as well as Klarite ${ }^{\mathrm{Tw}}$ gold and gold-copper bimetallic substrates were used for SERS analysis of aniline and nitroaniline isomers to investigate their chemisorption phenomena. Computational modeling based on Density Functional Theory (DFT) was used in conjunction with the SERS analysis to study the adsorption behaviors of the analytes on metal surfaces. Gold nanospheres and Klarite ${ }^{\text {Tw }}$ samples produced about a 10-fold increase in signal enhancement compared to gold nanostars for the SERS analysis of aniline, nitroaniline isomers, and nitrobenzene. Signal enhancement is significantly greater for aniline compared to nitrobenzene and it is dependent on the proximity of the $\mathrm{NH}_{2}$ to the $\mathrm{NO}_{2}$ group for the nitroaniline isomers. Charge-transfer in chemisorbed analytes is an important contributing factor for SERS signal. The relative strengths of enhancement can be predicted by the DFT calculation of the HOMO-LUMO energy gaps of the analyte-metal cluster. Aniline and the three nitroaniline isomers showed stronger preference for the copper substrates if both the gold and copper substrates are present. The $\mathrm{NO}_{2}$ group in 2-nitroaniline has a very strong preference and affinity for the copper in the $\mathrm{Au}-\mathrm{Cu}$ bimetallic cluster.
\end{abstract}

\section{Keywords}

Surface-Enhanced Raman Spectroscopy (SERS), Nitroaniline Isomers, Nanoparticles, Charge-Transfer, Chemisorption, Density Functional Theory (DFT)

\section{Introduction}

The underlying mechanisms responsible for Surfaced Enhanced Raman Spectroscopy (SERS) are related to the two important phenomena of electromagnetic enhancement and chemical enhancement. The introduction of laser and the progression of photon detection technologies have created a widespread interest 
in the utilization of Raman scattering as an analytical technique [1]. Noble metal substrates such as copper, gold, and silver are the most frequently used metal substrates. Computational methods have provided a quantitative basis for understanding the electromagnetic enhancement and predicting vibrational mode energies such as $\mathrm{C}-\mathrm{H}$ stretches, $\mathrm{C}-\mathrm{C}$ stretching, $\mathrm{C}-\mathrm{S}$ stretching, $\mathrm{C}-\mathrm{H}$ in-plane bending, $\mathrm{NO}_{2}$ bending, $\mathrm{NH}_{2}$ wagging, overtones, and combination bands [2]-[7].

The chemisorption phenomenon or chemical enhancement depends on the charge transfer between metal and the analyte that is adsorbed directly onto a roughened metal surface. Hence, the mechanism is site-specific and dependent on the analyte [1], its molecular interactions, orientation, steric hindrance, as well as the texture of the metal surface [2]. The charge transfer from metal to analyte or analyte to metal occurs because the HOMO (highest occupied molecular orbital) and LUMO (lowest unoccupied molecular orbital) of the adsorbates are similar in their energy levels with respect to the Fermi level of the metal [2] [8] [9] [10]. The chemical mechanism provides an average enhancement factor of 100 whereas the electromagnetic mechanism provides an average enhancement factor of equal or greater than 10,000 [11].

The electromagnetic (EM) or plasmonic enhancement effect requires that the Raman-active analyte be located within the EM field of the metal substrate. The morphologies of the metallic nanostructure such as size, shape, interparticle spacing, and surface textures of the substrate determine the resonant frequency of the electronic conduction within the metallic nanostructure [1]. When the localized surface plasmon resonance (LSPR) of the metal substrate is excited by visible light, the radiating electric field that is formed drives the conduction electrons into collective oscillation generating an intensified EM field. Raman-active molecules within the strong EM field exhibit an increase in the magnitude of their induced dipole and intensity of the inelastic scattering. Hence, the Raman signal from a molecule adsorbed on the surface of the metal is significantly amplified due to the excitation of the surface plasmon [2] [12] [13].

Studies using isomers with ortho, meta, and para-substituent groups showed that the analyte adsorption on the metal substrate could be intensely influenced by the surface characteristic (i.e. solid or liquid state) of the substrate and the orientation of the adsorbate with respect to the surface [4] [5] [6] [14] [15] [16]. Some of these effects with regard to nitroaniline derivatives are due to the relative distance between the amino group (electron-donating substituent) and the nitro group (electron-withdrawing substituent) on the benzene ring [5] [6]. Even though the ortho-, meta- and para-substituents of nitroaniline have the same molecular formula, their Raman spectra, enhancement factors, molecular orientation, and adsorption on the metal colloids such as gold or silver are different [4] [5] [6]. Besides silver and gold substrates, copper has also been shown to have a strong affinity for the nitrogen atom in the amino group of 4-aminobenzenethiol in a SERS study in which the metal substrates served as electrodes for investigating the variation of the SERS spectra as a function of 
electrochemical potentials applied onto the three different metal substrates. The strong affinity prevents the azo-bond formation between the nitrogen of adjacent molecules adsorbed on the copper substrate, whereas the same molecule adsorbed onto a silver or gold substrate will result in photocatalytic formation of 4,4'-dimercaptoazobenzene [3] [17]. Raman analysis using a copper substrate have revealed that a pyromellitic dianhydride molecule can chemisorb onto the copper substrate via a carboxylate group by the elimination of a $\mathrm{C}=\mathrm{O}$ group [2] [11].

Recent studies demonstrated the superiority of gold colloidal nanoparticles compared to the silver substrate in enhancing the SERS signals for compounds such as aniline derivatives, melamine, and 4-aminobiphenyl [9] [10]. Gold nanostars (ca $140 \mathrm{~nm}$ ) have been shown to have a stronger SERS activity compared to either the rod-shaped (length $\times$ width of ca $65 \mathrm{~nm} \times 30 \mathrm{~nm}$ ) or the spherical (ca $150 \mathrm{~nm}$ ) nanoparticles for 2-mercaptropyridine and crystal violet [7]. The non-linear dependence of SERS intensities on analyte concentrations was demonstrated for the SERS study of 2-mercaptropyridine and crystal violet. The non-linear relationships were observed at concentrations greater than $1.5 \mu \mathrm{M}$ for 2-mercaptropyridine and greater than $1.6 \mu \mathrm{M}$ for crystal violet. This can be attributed to the accumulation of excess analyte molecules beyond the saturation point of the surface monolayer resulting in the formation of additional layers that lowers both the electromagnetic and chemical contribution to the signal enhancement [7].

SERS spectra have been used to distinguish between isomers as well as for predicting the most favorable molecular orientation of adsorbate on the metal surfaces. Computational analysis is needed to aid in modeling how molecules are interacting with the nanoparticles during chemisorption. DFT (density functional theory) calculations and simulated Raman spectra have been used to study the chemical transformation of 4-aminobenzenethiol into 4,4'-dimercaptoazobenzene on silver nanoparticle surfaces [3] [18]. In this study, density functional theory (DFT) calculations were used to corroborate the experimental data as well as to elucidate the most relevant model for the chemisorption of the adsorbate on the substrate. The theoretical technique of computational modeling performs a key role in interpreting and perceiving the influences of the diverse elements on SERS mechanisms [4] [5] [6] [8] [10] [17] [19].

\section{Materials \& Methods}

\subsection{Chemicals and Preparation of Analyte Solutions}

Aniline at $99.5 \%$ purity as well as its ortho-, meta-, and para-substituents, which were at purity levels of $99.0 \%, 98 \%$, and $99.0 \%$, respectively, were purchased from Sigma Aldrich (St. Louis, MO). The 99\% purity nitrobenzene, the $99.9 \%$ purity gold (III) chloride trihydrate salt $\left(\mathrm{HAuCl}_{4}\right)$ and the $99.5 \%$ purity $N$-2-hydroxyethylpiperazine- $N$-2-ethanesulfonic acid (HEPES) were also acquired from Sigma Aldrich (St. Louis, MO). The trisodium citrate dehydrate, 
methanol, and ethanol from Acros Organics were purchased from Fisher Scientific (Suwanee, GA). Aniline was prepared as a 1000-ppm stock solution in deionized water before being diluted to $102 \mathrm{ppm}$. The 2-nitroaniline (1100 ppm), 3-nitroaniline $(833 \mathrm{ppm}), 4$-nitroanline $(800 \mathrm{ppm})$ and nitrobenzene (1800 $\mathrm{ppm})$ solutions were prepared by using deionized water.

\subsection{Preparation of Gold Nanostars}

Colloidal gold nanostars were prepared using the method described by Xie et al. with slight modification [20]. Gold nanostars were prepared by using $115 \mu \mathrm{L}$ of $24.25 \mathrm{mM}$ gold (III) chloride trihydrate solution that was slowly added as droplets into the 2:3 fold diluted $100 \mathrm{mM}$ HEPES solution ( $\mathrm{pH} 7.5 \pm 0.5$, adjusted with $1.0 \mathrm{M} \mathrm{NaOH}$ ). The reaction was allowed to progress without shaking or stirring for 20 minutes until dark purple star-like crystals formed indicating the end of the reaction.

\subsection{Preparation of Colloidal Gold Nanoparticles}

Colloidal gold nanoparticles were prepared using the Lee et al. method with minor modifications [21]. A 90-mL aqueous solution of $1.1 \mathrm{mM}$ gold (III) chloride trihydrate $\left(\mathrm{HAuCl}_{4}\right)$ was heated until boiling. Then a $10.2-\mathrm{mL} 10 \%$ ethanol-methanol mixture containing $120 \mathrm{mg}$ trisodium citrate dihydrate was slowly added to the rapidly boiling gold (III) chloride trihydrate $\left(\mathrm{HAuCl}_{4}\right)$ solution while stirring continuously and vigorously until a rust-red-brown chalky color change occurred. The mixture was left to cool for 15 minutes to at room temperature.

\subsection{Raman Spectroscopy Analysis}

Aqueous samples for SERS analysis were prepared in 2-mL vials using a 1:1 volume ratio of analyte solution to the gold nanostars or gold nanoparticles. Normal Raman signals were collected using neat analyte and solutions. The aniline (102 ppm or $\mathrm{mg} / \mathrm{kg}$ ), 2-nitroaniline (1100 ppm), 3-nitroaniline (833 ppm), 4-nitroanline $(800 \mathrm{ppm})$ and nitrobenzene $(1800 \mathrm{ppm})$ solutions were also analyzed on Klarite ${ }^{\mathrm{TM}}$ chips (Renishaw Diagnostics Ltd., Glasgow, UK) by meticulously placing $1 \mu \mathrm{L}$ at a time using a $10 \mu \mathrm{L}$-Hamilton syringe. The enhancement effect of copper was determined by mixing a drop of $2-\mu \mathrm{L}$ gold colloidal nanoparticles with $2 \mu \mathrm{L}$ analyte on a copper wafer. The wafer was cleaned using $6 \mathrm{M}$ $\mathrm{HCl}$ prior to analysis.

The Raman spectra were collected using the EnWave ProRaman-L spectrometer (EnWave Optronics Inc., Irvine, CA) equipped with a fiber-optic probe and a laser with an excitation wavelength of $785 \mathrm{~nm}$ and line width of $0.04 \mathrm{~nm}$. The signals were collected with integration times of 5, 10,30, 60, and 120 seconds while the samples were wet and when dried on the Klarite ${ }^{\mathrm{TM}}$ or copper wafer. Spectra were displayed using Thermo Electron's OMNIC 7.0 software via the "full scale" and "spectra offset" modes; peak areas were obtained with the 
signal integration tool.

\subsection{Computational Analysis}

Molecular structures of aniline, nitrobenzene, and 1-, 2-, and 3-nitroaniline, as well as their complexes with $4 \mathrm{Au}$ and $5 \mathrm{Au} 5 \mathrm{Cu}$ clusters, were constructed using SPARTAN10 (Spartan'10 Wavefunction, Inc., Irvine, CA). Except for molecular mechanics and semi-empirical models, the calculation methods used in Spartan were done according to method documented in Shao et al. [22] and then imported into Gaussian09 Revision C.01 [23]. Each of the free anilines and nitrobenzene structures were then optimized using the B3LYP density functional [24] and the $6-311++G(d, p)$ [25] basis set. The structures of the cluster complexes were also optimized using the B3LYP functional and the $6-311++\mathrm{G}(\mathrm{d}, \mathrm{p})$ basis set for the anilines and the LANL2DZ [26] [27] basis set for the gold and silver atoms. Vibrational frequencies and Mulliken charges [28] for all structures were also calculated using the B3LYP/(6-311++G(d,p)/LANL2DZ) level of DFT. Raman vibrational modes were assigned visually using GaussView 5 (GaussView 5.0.9, Gaussian, Inc. Wallingford, CT).

\section{Results and Discussion}

\subsection{Dependence of SERS Signal Intensities on Different Gold Nanostructures}

Surface enhancement Raman spectroscopy technique relies on the application of a metal substrate such as gold, silver, or copper to enhance the Raman signal of an analyte by as much as $10^{4}$ to $10^{6}$ fold and even up to $10^{10}$ fold depending on the specific analytical conditions [29] [30] [31] [32]. There are many different SERS substrates and some are even available commercially. The popularity of using the SERS technique for analytical measurements is due in part to the availability of commercially prepared substrates and the ease of preparing many of these substrates in the laboratory to achieve signal enhancement needed to detect or quantify analytes at low concentrations. In this study, various gold substrates were evaluated for the SERS analysis of aniline and nitroaniline isomers. Figure 1 shows that the strongest signals for detecting $102 \mathrm{ppm}$ of aniline were obtained using Klarite ${ }^{\mathrm{TM}}$ or with colloidal nanospheres. It also shows that gold nanospheres and gold nanostars give different degrees of Raman signal enhancement for aniline. This observation is consistent with the previously reported finding that the preparation method for the nanostructures affects the intensity of the SERS signals [7].

The present study also found that the degree of enhancement is also analyte dependent since different isomers of nitroaniline with the same gold substrates preparations have different levels of enhancement. The enhancement factors along with the experimental and predicted wavenumbers of the normal Raman and SERS signals for aniline and three nitroaniline isomers are summarized in Table 1. It is observed that the SERS signals of 2-nitroaniline generally has the 


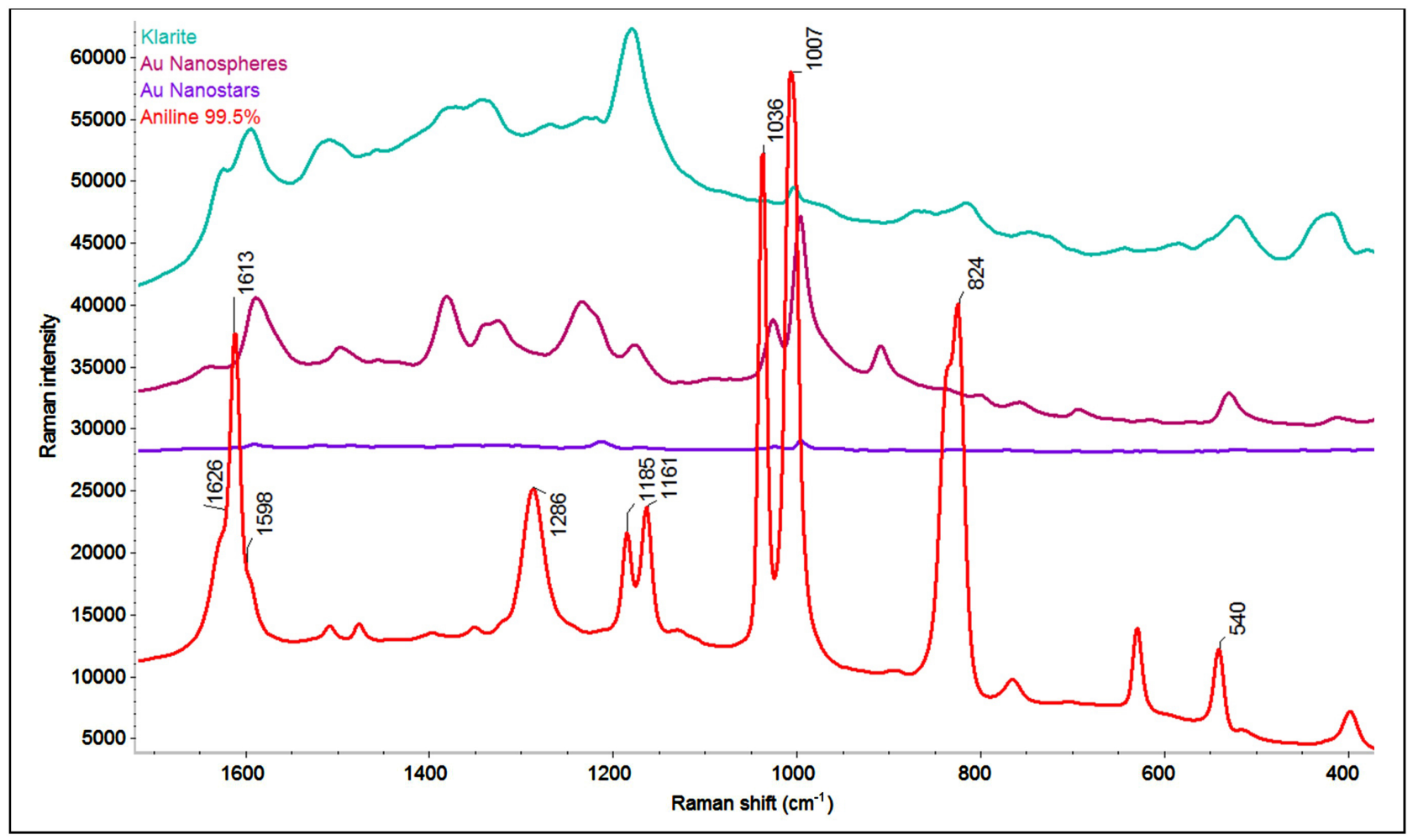

Figure 1. Normal and SERS spectra of aniline analyzed using different types of substrate. Spectra for gold nanostars and nanospheres were obtained using 1 to 1 volume ratio of $102 \mathrm{ppm}$ aniline to nanoparticles solution in a vial (final volume $1.0 \mathrm{~mL}$ ). The spectrum for Klarite ${ }^{\mathrm{TM}}$ was obtained using $1 \mu \mathrm{L}$ of $102 \mathrm{ppm}$ aniline solution. Normal Raman was obtained using $99.5 \%$ aniline. The Raman spectra, shown on a common scale, were collected using the same laser power setting and 30 seconds if integration time.

highest enhancement factors compared to the other two isomers for the three types of SERS substrates. All three isomers displayed at least a 10-fold increase in enhancement factor with gold nanospheres and Klarite ${ }^{\mathrm{TM}}$ compared with the nanostar substrate. SERS signals obtained using the Klarite ${ }^{\mathrm{TM}}$ substrate tend to have a greater extent of peak broadening and partially resolved peaks compared to the normal Raman spectra. On the contrary, SERS signals obtained using colloidal nanospheres tend to have sharper and more distinct peaks (Figure 2) making the spectral pattern of each isomers easily distinguishable from one another. Despite that, the spectral pattern obtained with Klarite ${ }^{\mathrm{TM}}$ was still distinguishable for each isomers (Figure A1 in Appendix A). The advantage of using Klarite ${ }^{\mathrm{TM}}$ is that a very small analyte volume of $1 \mu \mathrm{L}$ is sufficient to produce a strong signal. However, it is very difficult to precisely aim the laser beam from the fiber-optic probe onto a $1 \mu \mathrm{L}$ sample on the Klarite $^{\mathrm{TM}}$ with the laser beam. Nanospheres have greater stability or a longer shelf life, can withstand vigorous mixing and are still active after 2 weeks from the time they were prepared. Nanostars on the other hand are easy to prepare but are prone to structural deformation so they must be pipetted and mixed gently. Generally, nanostars are formed in clusters and each preparation will contain an uneven distribution of nanostars. Stirring or mixing may cause the prongs on the nanostar 


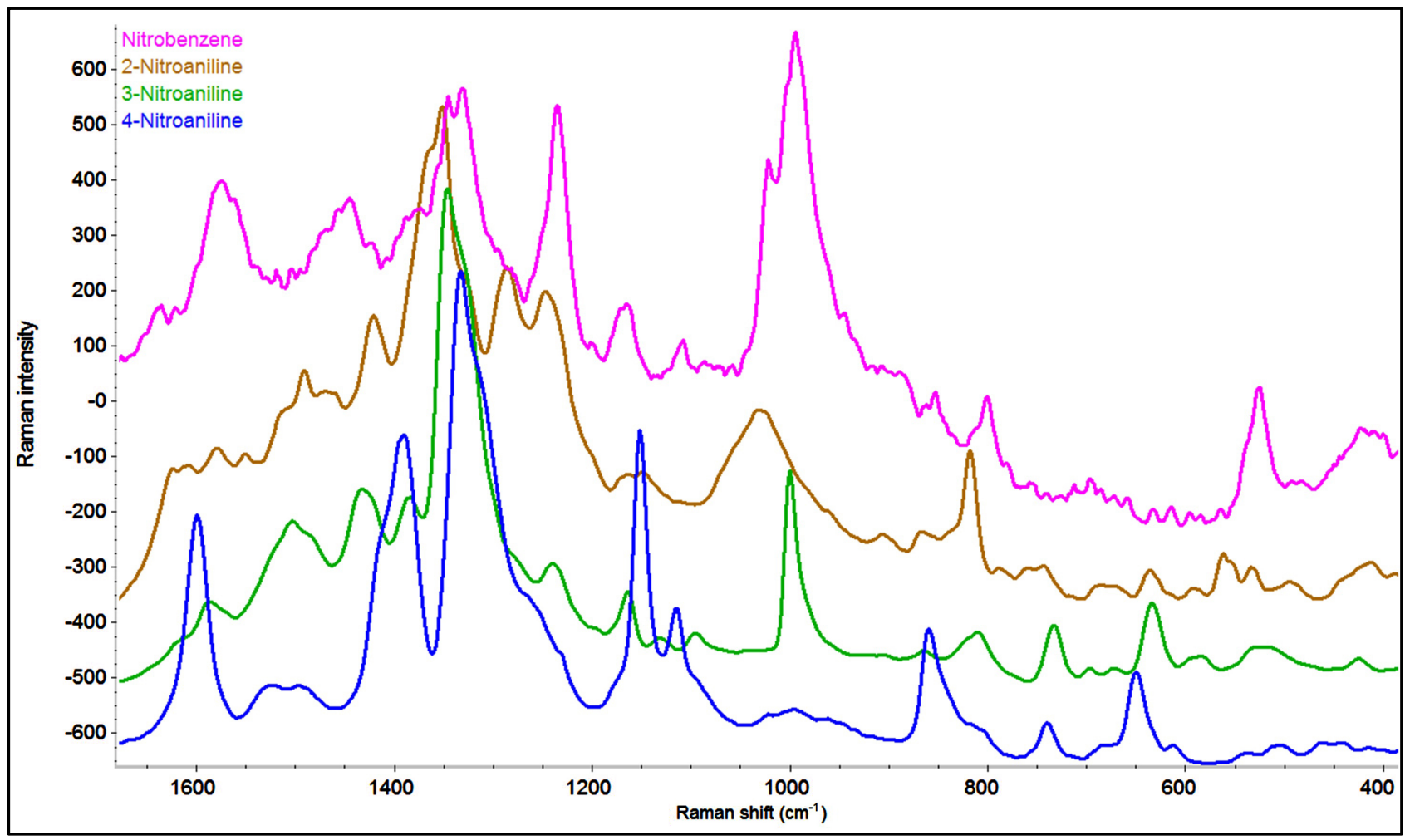

Figure 2. Raman spectra of nitroaniline isomers and nitrobenzene for SERS analysis with colloidal gold nanospheres. The spectra were collected using a 1 to 1 volume ratio of analyte to colloidal gold nanospheres in a vial (final volume $1.0 \mathrm{~mL}$ ). The concentration of the analytes was as follows: 800 ppm 4-nitroaniline, 833.3 ppm 3-nitroaniline, 1100 ppm 2-nitroaniline, and 1800 ppm nitrobenzene. The Raman spectra shown in full scale with offset mode were collected using the same laser power settings and 30 seconds of integration time.

structures to break. Nanostars have a short self-life and must be prepared fresh for use. Table 2 indicates that when both the $\mathrm{NH}_{2}$ group and the $\mathrm{NO}_{2}$ group are present on the nitroaniline isomers (i.e. 2-nitroaniline, 3-nitroaniline and 4-nitroaniline), the preferred chemisorptive interaction between the SERS substrate and the analyte molecules depends upon the position of the $\mathrm{NO}_{2}$ group relative to the $\mathrm{NH}_{2}$ group. The chemisorptive interactions produced the strongest signal enhancement if the two groups are closest together in the molecule as in 2-nitroaniline and the least enhancement if the groups are furthest apart as in the 4-nitroaniline (Table 1).

In general, the frequency shift in the vibrational mode of adsorbed analytes in SERS compared to free or solvated analyte molecules in normal Raman are interpreted as adsorption strength in the chemisorption process. The spectral shift is due to the structural changes taking place through the analyte bond formation with the metal substrate. Bond formation between $\mathrm{Au}, \mathrm{Ag}$, or $\mathrm{Cu}$ substrates and adsorbate can occur as in metal-nitrogen, metal-oxygen, metal-sulfur, or metal-halogen bonds. In some cases, the group and aromatic ring can form a $\pi$ bond with the metal nanostructures [5] [15] [16] [17]. In this (see Table 1) and previous studies [9] [10] [33] [34], introduction of a blue shift of the normal or bulk Raman signal by as much as $456 \mathrm{~cm}^{-1}$ (i.e. $540 \mathrm{~cm}^{-1}$ to $996 \mathrm{~cm}^{-1}$ ) was observed 
Table 1. Comparison of enhancement factors of analytes with different gold substrate type.

\begin{tabular}{|c|c|c|c|c|c|c|c|}
\hline \multirow{2}{*}{$\begin{array}{l}\text { Aromatic } \\
\text { Amines }\end{array}$} & \multicolumn{2}{|c|}{$\begin{array}{c}\text { Raman Spectra } \\
\text { Wavenumber }\left(\mathrm{cm}^{-1}\right)\end{array}$} & \multicolumn{2}{|c|}{$\begin{array}{c}\text { SERS Spectra } \\
\text { Wavenumber }\left(\mathrm{cm}^{-1}\right)\end{array}$} & \multirow{2}{*}{$\begin{array}{c}\text { Au Nanostars } \\
\text { Enhancement } \\
\text { Factor }\end{array}$} & \multirow{2}{*}{$\begin{array}{c}\mathrm{Au} \\
\text { Nanospheres } \\
\text { Enhancement } \\
\text { Factor }\end{array}$} & \multirow{2}{*}{$\begin{array}{c}\text { Klarite }^{\mathrm{TM}} \\
\text { Enhancemen } \\
\text { Factor }\end{array}$} \\
\hline & Theo. & Expt. & Theo. & Expt. & & & \\
\hline \multirow{6}{*}{ Aniline } & 575 & 540 & 1046 & 996 & $3.98 \times 10^{3}$ & $6.84 \times 10^{4}$ & $2.13 \times 10^{4}$ \\
\hline & 830 & 824 & 812 & 824 & $8.18 \times 10^{1}$ & $4.69 \times 10^{2}$ & $7.31 \times 10^{2}$ \\
\hline & 1010 & 1007 & 1015 & 960 & $8.15 \times 10^{1}$ & $2.17 \times 10^{3}$ & $2.62 \times 10^{2}$ \\
\hline & $1047 / 1179 / 1200$ & $1036 / 1161 / 1185$ & $1048 / 1185 / 1201$ & $1025 / 1144 / 1172$ & $2.63 \times 10^{2}$ & $3.85 \times 10^{3}$ & $9.34 \times 10^{2}$ \\
\hline & 1297 & 1286 & 1235 & 1214 & $7.97 \times 10^{2}$ & $8.18 \times 10^{3}$ & $1.76 \times 10^{3}$ \\
\hline & $1625 / 1644 / 1663$ & $1598 / 1613 / 1626$ & $1643 / 1642 / 1651$ & $1558 / 1571 / 1592$ & $3.08 \times 10^{2}$ & $6.04 \times 10^{3}$ & $1.76 \times 10^{3}$ \\
\hline \multirow{8}{*}{ 2-Nitroaniline } & 181 & OSR $^{*}$ & 263 & OSR $^{*}$ & $\mathrm{NA}^{*}$ & $\mathrm{NA}^{*}$ & $\mathrm{NA}^{*}$ \\
\hline & 833 & 817 & 836 & 817 & $2.86 \times 10^{2}$ & $8.73 \times 10^{2}$ & $1.82 \times 10^{3}$ \\
\hline & $1072 / 1179 / 1192$ & $1068 / 1160 / 1176$ & $1070 / 1186 / 1195$ & $1048 / 1179 / 1195$ & $2.57 \times 10^{2}$ & $2.94 \times 10^{3}$ & $1.42 \times 10^{3}$ \\
\hline & 1287 & 1247 & 1270 & 1255 & $1.03 \times 10^{2}$ & $9.61 \times 10^{2}$ & $9.46 \times 10^{2}$ \\
\hline & 1304 & 1287 & 1309 & 1285 & $2.07 \times 10^{2}$ & $1.83 \times 10^{3}$ & $8.96 \times 10^{2}$ \\
\hline & 1373 & 1355 & 1359 & 1349 & $3.19 \times 10^{2}$ & $1.34 \times 10^{3}$ & $6.40 \times 10^{2}$ \\
\hline & 1385 & 1390 & 1397 & 1368 & $7.29 \times 10^{2}$ & $3.08 \times 10^{3}$ & $8.25 \times 10^{2}$ \\
\hline & $1603 / 1615 / 1663$ & 5 1571/1630/1608 & $1600 / 1624 / 1662$ & $1521 / 1608 / 1571$ & $1.40 \times 10^{3}$ & $3.02 \times 10^{3}$ & $1.68 \times 10^{3}$ \\
\hline \multirow{7}{*}{ 3-Nitroaniline } & 494 & 496 & 464 & 483 & $\mathrm{NA}^{*}$ & $3.42 \times 10^{3}$ & $2.27 \times 10^{3}$ \\
\hline & 833 & 827 & 839 & 808 & $5.23 \times 10^{1}$ & $2.27 \times 10^{3}$ & $7.83 \times 10^{2}$ \\
\hline & 1010 & 1004 & 1009 & 996 & $1.02 \times 10^{2}$ & $3.64 \times 10^{3}$ & $1.06 \times 10^{3}$ \\
\hline & $1076 / 1126 / 1191$ & $1080 / 1171 / 1230$ & $1077 / 1128 / 1194$ & $1043 / 1162 / 1216$ & $2.33 \times 10^{2}$ & $3.26 \times 10^{3}$ & $7.41 \times 10^{3}$ \\
\hline & 1293 & 1273 & 1299 & 1270 & $6.15 \times 10^{1}$ & $1.36 \times 10^{3}$ & $1.22 \times 10^{2}$ \\
\hline & 1370 & 1359 & 1309 & 1345 & $7.79 \times 10^{1}$ & $2.29 \times 10^{3}$ & $3.95 \times 10^{2}$ \\
\hline & $1621 / 1656 / 1670$ & $1590 / 1616 / 1635$ & $1615 / 1669 / 1652$ & $1612 / 1622 / 1646$ & $3.78 \times 10^{1}$ & $6.90 \times 10^{2}$ & $3.28 \times 10^{2}$ \\
\hline \multirow{7}{*}{ 4-Nitroaniline } & 390 & 406 & 243 & $\mathrm{OSR}^{*}$ & $\mathrm{NA}^{*}$ & $\mathrm{NA}^{*}$ & $\mathrm{NA}^{*}$ \\
\hline & 875 & 865 & 878 & 859 & $1.15 \times 10^{1}$ & $1.06 \times 10^{2}$ & $9.74 \times 10^{1}$ \\
\hline & $1062 / 1148 / 1205$ & $1049 / 1141 / 1181$ & $1049 / 1154 / 1207$ & $1045 / 1148 / 1175$ & $1.40 \times 10^{1}$ & $1.81 \times 10^{2}$ & $1.32 \times 10^{2}$ \\
\hline & 1325 & 1322 & 1347 & 1316 & 8.28 & $6.37 \times 10^{1}$ & $4.06 \times 10^{1}$ \\
\hline & 1358 & 1283 & 1303 & 1332 & $2.23 \times 10^{1}$ & $1.73 \times 10^{2}$ & $9.45 \times 10^{1}$ \\
\hline & 1373 & 1341 & 1379 & 1379 & $1.20 \times 10^{1}$ & $2.22 \times 10^{2}$ & $2.25 \times 10^{2}$ \\
\hline & $1633 / 1641 / 1665$ & $1554 / 1596 / 1635$ & $1617 / 1643 / 1665$ & $1572 / 1596 / 1626$ & $3.59 \times 10^{1}$ & $3.41 \times 10^{2}$ & $1.08 \times 10^{2}$ \\
\hline \multirow{5}{*}{ Nitrobenzene } & 868 & 859 & 877 & 860 & 1.95 & 9.41 & $1.49 \times 10^{1}$ \\
\hline & 1018 & 1009 & 1017 & 1010 & 4.74 & $2.81 \times 10^{1}$ & 5.85 \\
\hline & $1042 / 1185 / 1196$ & $1030 / 1169 / 1182$ & $1042 / 1188 / 1199$ & $1023 / 1151 / 1177$ & $1.43 \times 10^{1}$ & $4.59 \times 10^{1}$ & $1.84 \times 10^{2}$ \\
\hline & 1371 & 1354 & 1305 & 1339 & 4.41 & 2.94 & 7.57 \\
\hline & $1583 / 1628 / 1652$ & $1533 / 1595 / 1620$ & $1552 / 1627 / 1643$ & $1547 / 1590 / 1616$ & 3.57 & $1.31 \times 10^{1}$ & $4.55 \times 10^{1}$ \\
\hline
\end{tabular}

MDL means below minimum detection limit. Enhancement factors for 2-nitroaniline with AuCu bimetallic substrates ranged from $1.34 \times 10^{3}$ to $2.73 \times 10^{4}$ which also corresponded with the lowest $\left(817 \mathrm{~cm}^{-1}\right)$ to highest wavenumbers. The vibrational mode assignment is listed in Table A1 (see Appendix A). $\mathrm{OSR}^{\star}$ : Outside spectrometer range; $\mathrm{NA}^{*}$ : Not applicable due to out-of-range or unresolved SERS signal. 
Table 2. DFT modeling of analyte orientations with respect to the metal substrate and the HOMO-LUMO energy gaps.

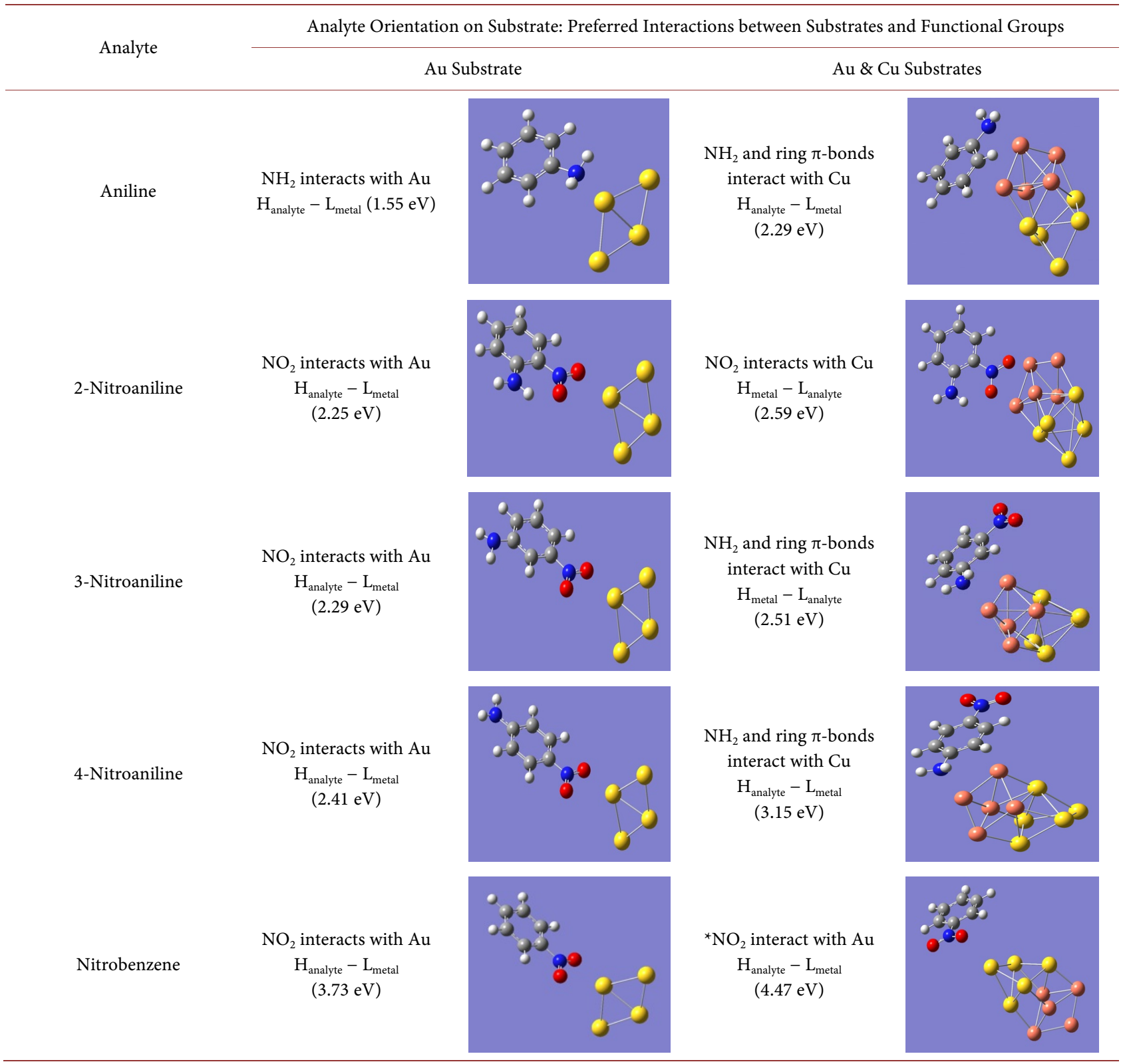

The orientation of the analyte with respect to the metal substrate is based on matching the spectrum predicted by the DFT calculation with the experimentally derived spectrum. The HOMO-LUMO energy gaps are listed in parenthesis. In the case of the Au clusters, the HOMO of the analyte $\left(\mathrm{H}_{\text {analyte }}\right)$ and the LUMO of the metal $\left(\mathrm{L}_{\text {metal }}\right)$ energy differences are listed. These energy differences are the smaller energy gap for all except nitrobenzene for which the energy gap between the metal HOMO and analyte LUMO is the smaller (3.24 eV). In the modeling of AuCu bimetal clusters, the Mulliken charge data (see Appendix A) indicates that the charge transfer is from the HOMO of the AuCu cluster $\left(\mathrm{H}_{\text {metal }}\right)$ to the LUMO of the analyte $\left(\mathrm{L}_{\text {analtye }}\right)$, which is the smaller energy gap for 2-nitroaniline and 3-nitroaniline. The Mulliken charge data for aniline is also in agreement with the use of HOMO-LUMO energy gap in determining that the charge transfer is from the analyte HOMO to the metal LUMO. ${ }^{*}$ Detected two different types of interactions in the experimental spectrum although the DFT modeling of gold interacting with nitrobenzene shows adsorption via the two oxygen atoms of the $\mathrm{NO}_{2}$ group.

for the $\mathrm{NH}_{2}$ wagging mode (Table A1 in Appendix A) in the SERS spectrum of aniline. This large shift was also predicted by the DFT-calculation and it corresponds with the largest enhancement factor of aniline for the $\mathrm{NH}_{2}$ wagging mode. This suggests that the strongest interaction between aniline and the metal surface is via its $\mathrm{NH}_{2}$ group. 
The SERS enhancement factor for the $\mathrm{NH}_{2}$ wagging mode of aniline was 20 times smaller than that of 3-nitroaniline for gold nanospheres and 10 times smaller in the case of Klarite ${ }^{\mathrm{TM}}$ substrates. This suggests that the presence of the nitro group in the nitroaniline isomers reduces or eliminates the charge transfer interaction via the $\mathrm{NH}_{2}$ group. This deduction is also consistent with the computational clue that the DFT calculation for the $\mathrm{NH}_{2}$ wagging mode of 3-nitroaniline and 4-nitroaniline predicted only small red shifts of $30 \mathrm{~cm}^{-1}$ and $147 \mathrm{~cm}^{-1}$ (i.e. $494 \mathrm{~cm}^{-1}$ to $464 \mathrm{~cm}^{-1}$ and $390 \mathrm{~cm}^{-1}$ to $243 \mathrm{~cm}^{-1}$ ), respectively. This suggests that the interactions between the metal and $\mathrm{NH}_{2}$ group of these two nitroaniline isomers are minimal compared to aniline that has spectral shifts of $456 \mathrm{~cm}^{-1}$ experimentally and $471 \mathrm{~cm}^{-1}$ theoretically. For 2-nitroaniline, a blue shift of $82 \mathrm{~cm}^{-1}$ (i.e. $181 \mathrm{~cm}^{-1}$ to $263 \mathrm{~cm}^{-1}$ ) was predicted. This value was smaller than the blue shift of aniline at $456 \mathrm{~cm}^{-1}$, suggesting that the interaction of the $\mathrm{NH}_{2}$ group with gold surface is greatly diminished. In summary, the DFT studies and SERS enhancement factors predicted that the preferred interactions between gold metal surface and the meta-nitroaniline and para-nitroaniline isomers are via their $\mathrm{NO}_{2}$ groups (Table 2) whereas ortho-nitroaniline interacts with gold via $\mathrm{NO}_{2}$ and possibly the $\mathrm{NH}_{2}$ groups due to proximity of the two groups. The trend of SERS enhancement factors (i.e. 2-nitroaniline > 3-nitroaniline > 4-nitroaniline) is inversely related to the degree of separation between the $\mathrm{NH}_{2}$ and the $\mathrm{NO}_{2}$ group (see Table 1). In the case of nitrobenzene, the enhancement factor is the smallest because the nitro group is not efficiently involved in the charge transfer to the metal like the amino group in the case of aniline or nitroanilines. Thus, one can infer that the presence and proximity of the $\mathrm{NH}_{2}$ group to the $\mathrm{NO}_{2}$ group increases the enhancement factor of the analytes.

The ability to reliably predict the magnitude of SERS enhancement factors by using DFT modeling is crucial to the fundamental understanding of the chemisorption phenomena involving analytes adsorbed on SERS-active surfaces of gold, silver, and copper. The molecular modeling of adsorbed analytes by DFT not only allows the prediction of Raman shift of bulk and adsorbed analytes for different vibrational modes, it also allows the calculation of the energy gap between the HOMO of the analytes and the LUMO of the metal and the Mulliken charges on the various atoms of the analyte molecules [35]. Both these parameters elucidate the chemisorption phenomena and contribute to predicting the strengths of the chemical enhancement effect. In the case of aniline, explanation for the strong interactions between the $\mathrm{NH}_{2}$ group and the gold substrate is based on the charge transfer between the lone pair electrons from the nitrogen atom of the $\mathrm{NH}_{2}$ group to the metal. The charge transfer of aniline in SERS analysis can be attributed to the optimal orbital overlap as a result of small energy difference of $1.55 \mathrm{eV}$ between the HOMO of aniline and the LUMO of metal [33]. As shown in Table 2, aniline has the smallest HOMO-LUMO energy gap compared to the three isomers of nitroaniline and nitrobenzene. The increasing order of HOMO-LUMO energy gap from smallest to largest was found 
to be aniline $<2$-nitroaniline $<3$-nitroaniline $<4$-nitroaniline $<$ nitrobenzene. This order of the HOMO-LUMO energy gap explains the decreasing order of enhancement factors from aniline to nitrobenzene because the strength of the charge transfer is related to the energy gap or effectiveness of orbital overlap between the chemisorbed analyte and the metal. The smaller the energy gap, the greater the degree of orbital overlap and consequently the stronger the charge transfer interaction. The various mechanisms of the SERS phenomenon arising from chemical and electromagnetic enhancement for many types of compounds, including aromatic amines, have been reviewed recently [36]. It is important to point out the relative contribution of different mechanisms varies for different molecular structures. For the aniline, nitrobenzene, and nitroanilines described in this study, the HOMO-LUMO energy gaps and charge transfer effects have predominant influence on both the SERS intensities and vibrational shifts.

For the nitroaniline isomers, their HOMO-LUMO energy gaps of $2.25 \mathrm{eV}$ for 2-nitroaniline, $2.29 \mathrm{eV}$ for 3-nitroaniline, and $2.41 \mathrm{eV}$ for 4-nitroaniline closely parallels the order of the interaction strength and enhancement factor relative to aniline. Nitrobenzene on the other hand has the largest energy gap of $3.73 \mathrm{eV}$ and the lowest enhancement effect. This implied that the orbital overlap is far from optimal resulting in weak interaction between the $\mathrm{NO}_{2}$ group of nitrobenzene and gold. Even though electrons are drawn away from the $\mathrm{N}$ and $\mathrm{O}$, the charge transfer towards the metal is comparatively small as indicated by the Mulliken charge data (see Table A2). There is a charge transfer of 0.422 e from aniline to the gold cluster as a result of the aniline-gold interaction whereas the charge transfer from nitrobenzene to gold cluster is only 0.265 e for the nitrobenzene-gold interaction. Hence, aniline-gold interactions are significantly stronger than nitrobenzene-gold interaction. The increasing degree of charge transfer from analyte to gold was in the order of aniline $(0.422 \mathrm{e})>2$-nitroaniline $(0.310$ e) > 4-nitroaniline $(0.296 \mathrm{e})>3$-nitroaniline $(0.276 \mathrm{e})>$ nitrobenzene $(0.265 \mathrm{e})$. Since charge transfer is also an indication of the strength of analyte-metal interaction that contributes to signal enhancement, the charge transfer magnitude estimated by DFT can provide an insight or explanation for the experimental observation of the SERS enhancement factors. Although the Mulliken charge transfer for 4-nitroaniline is greater than that for 3-nitroaniline, the signal enhancement factors in Table 1 show that 3-nitroaniline adsorbed on gold substrate has about a ten-fold stronger signal enhancement relative to 4-nitroaniline. This implies that other contributing factors to signal enhancement such as the electromagnetic or plasmonic effect [37] [38] as a result of the incoming laser excitation of the electrons on the gold surface, which activates the surface plasmons or the collective oscillations of the electrons, may have been more significant in the case of 3-nitroaniline. The proximity of the $\mathrm{NH}_{2}$ group to the $\mathrm{NO}_{2}$ group on the nitroaniline isomers can affect the adsorption orientation of the isomers on the metal surface and influence SERS signal enhancement [6]. 


\subsection{SERS Signal with Gold-Copper Bimetal Substrates}

Earlier studies have explored the use of bimetallic substrates for improving SERS activity. Such bimetallic nanostructures included Ag/Au alloys [39] [40], Ag-coated Au particles [41], Ag-coated Au as well as Au-coated Ag colloids [42], $\mathrm{Ag} / \mathrm{Au}$ bimetallic hollow nanostructure [43] and $\mathrm{Ag} / \mathrm{Au}$ film on Si wafer [44]. SERS spectra of analytes adsorbed onto a substrate of gold colloidal nanospheres supported on a copper foil show peak broadening and overlapped peaks in the region from 1100 - 1600 wavenumbers like the SERS spectra obtained using Klarite $^{\text {TM }}$ (Figure 3 ). The same analyte, 2-nitroaniline produced spectra with more distinctly resolved peaks when used with gold nanospheres alone. The purpose of using the SERS substrate of gold nanospheres supported on a copper foil is to determine whether aniline and nitroaniline isomers prefer the gold or the copper when both metal surfaces are available and whether the SERS spectra of the isomers are still easily distinguishable despite peak broadening and merging. Figure 4 shows that the isomers are all easily distinguishable from one another using the Au nanospheres-copper mixed substrate method. Therefore, the technique of using colloidal gold nanospheres on top of copper foil is an alternative technique that can replace the Klarite ${ }^{\mathrm{TM}}$ substrate where strong SERS signal can be obtained using only a $1-2 \mu \mathrm{L}$ analyte solution. Klarite-based SERS spectra also

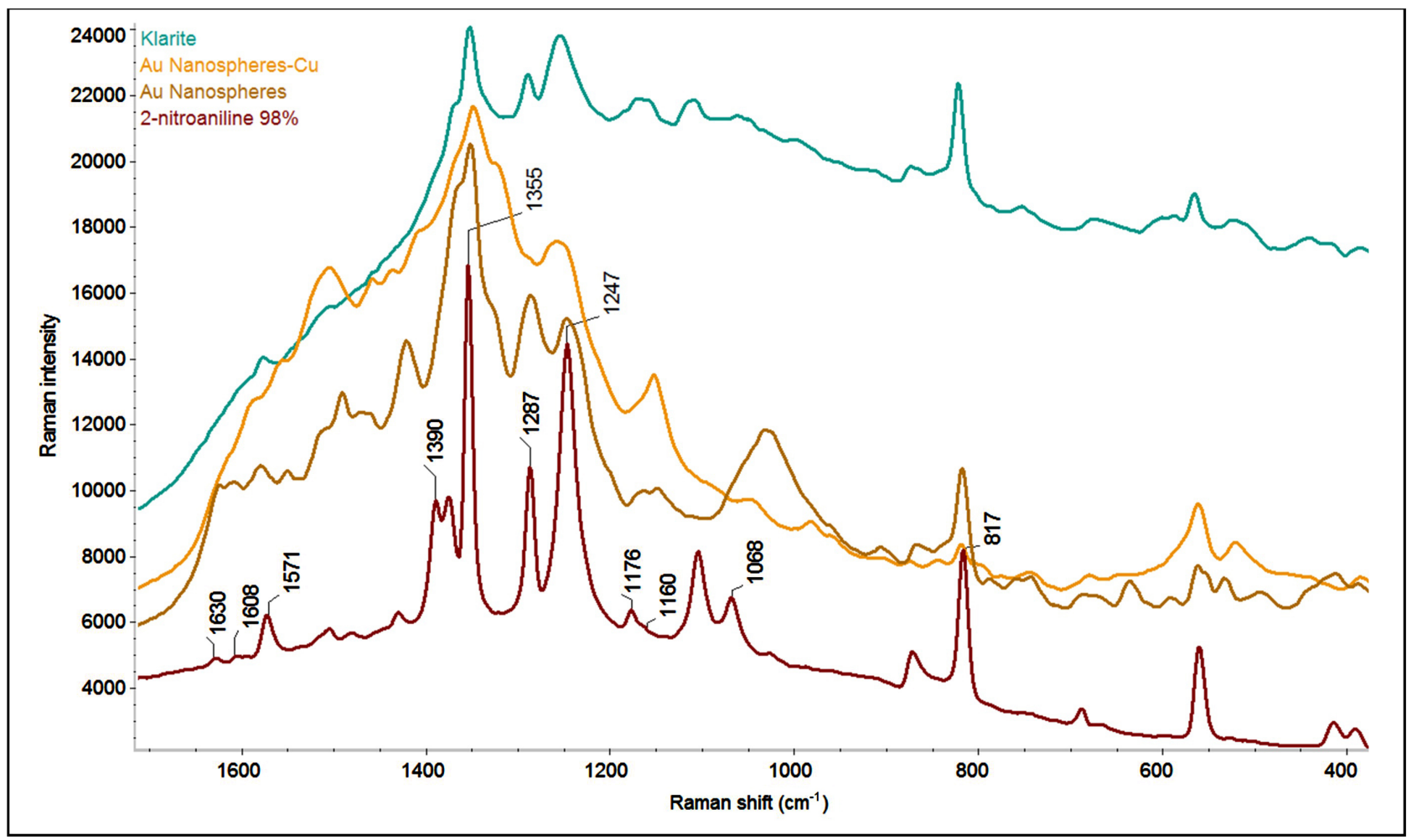

Figure 3. Normal and SERS spectra of 2-nitroaniline acquired with gold and gold-copper mixed substrates. The SERS spectra were collected for samples containing $1100 \mathrm{ppm} 2$-nitroaniline at 1 to 1 volume ratio with colloid nanospheres in a vial (1.0 mL final volume) or on copper foil ( $4 \mu \mathrm{L}$ final volume). The normal Raman signal was obtained using a neat sample of $98.0 \%$ purity 2-nitroaniline. The spectra were collected using the same laser power setting of the Raman spectrometer and 30 seconds of integration time. The spectra are shown in full scale with offset for greater clarity of spectral features. 


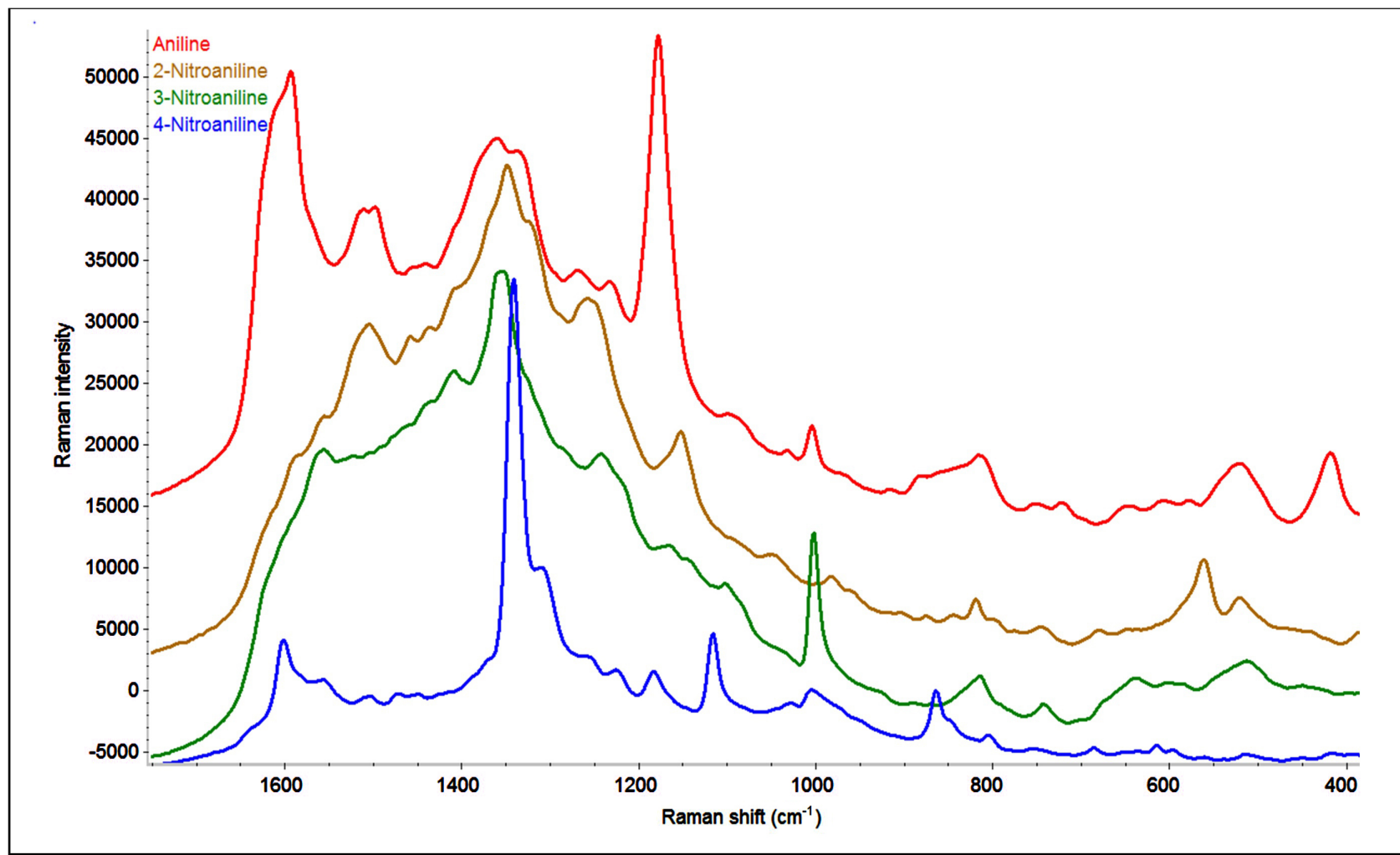

Figure 4. SERS spectra of aniline and nitroaniline isomers adsorbed onto gold nanospheres supported on a copper foil substrate. The spectra were collected using a 1 to 1 volume ratio of analyte to colloidal nanospheres (final volume $4 \mu \mathrm{L}$ ) on copper foil. The concentration of the analytes was as follows: 102 ppm aniline, $833.3 \mathrm{ppm} 3$-nitroaniline, 1100 ppm 2-nitroaniline and 800 ppm 4-nitroaniline. All spectral signals were collected using the same laser power settings and 30 seconds of integration time except for 4-nitroaniline that has an integration time of 5 seconds. The SERS spectra were overlaid in full scale with offset mode using OMNIC 9 software.

tend to induce high background interference as a combination of analyte fluorescence and substrate reflectance whereas there is less background interference with the Au-Cu mixed substrates (Figure 3 \& Figure 4). DFT-modeling predicted (Table 2) that aniline and the three nitroaniline isomers all preferred the copper over the gold surface when both metals are available. Nitrobenzene, on the other hand, preferred gold to the copper substrate. Except for 2-nitroaniline, the $\mathrm{NO}_{2}$ group of the adsorbate does not like to interact with the copper surface. The Mulliken charge data (Appendix A, Table A3) is in agreement with the smaller HOMO-LUMO energy gap of $2.29 \mathrm{eV}, 2.59 \mathrm{eV}$ and $2.51 \mathrm{eV}$ for aniline, 2-nitroaniline and 3-nitroaniline, respectively. The data indicates a charge transfer from the HOMO of the analyte to the LUMO of the metal cluster for aniline, 4-nitroaniline and nitrobenzene but a charge transfer from the HOMO of the metal cluster to the LUMO of the analyte for 2-nitroaniline and 3-nitroaniline. Table 2 shows the DFT prediction for the SERS signals of aniline, 3-nitroaniline, and 4-nitroaniline that are produced through the preferential interact with the copper via the $\mathrm{NH}_{2}$ group bonding as well as $\pi$-bonding with the aromatic ring. The SERS signal for 2-nitroaniline is produced via its $\mathrm{NO}_{2}$ group bonding with the copper in the $\mathrm{AuCu}$ bimetal cluster. The DFT calculation per- 
formed on 2-nitroaniline for gold-copper substrates with the $\mathrm{NH}_{2}$ group initially arranged in proximity to the gold and away from the copper side showed that the molecule will rotate as well as migrate until its $\mathrm{NO}_{2}$ group is in proximity to the copper side (Figure 5). If the DFT-calculation was performed with the $\mathrm{NH}_{2}$ group initially facing the copper side while the gold is on the other side, then the molecule will shift its position slightly towards the $\mathrm{NO}_{2}$ group such that $\mathrm{NO}_{2}$ functional group is also interacting with the copper. This is similar to the study on the 4-aminobenzenethiol molecule, which demonstrated that the $\mathrm{N}$ atom in that molecule has a very strong affinity for copper [17].
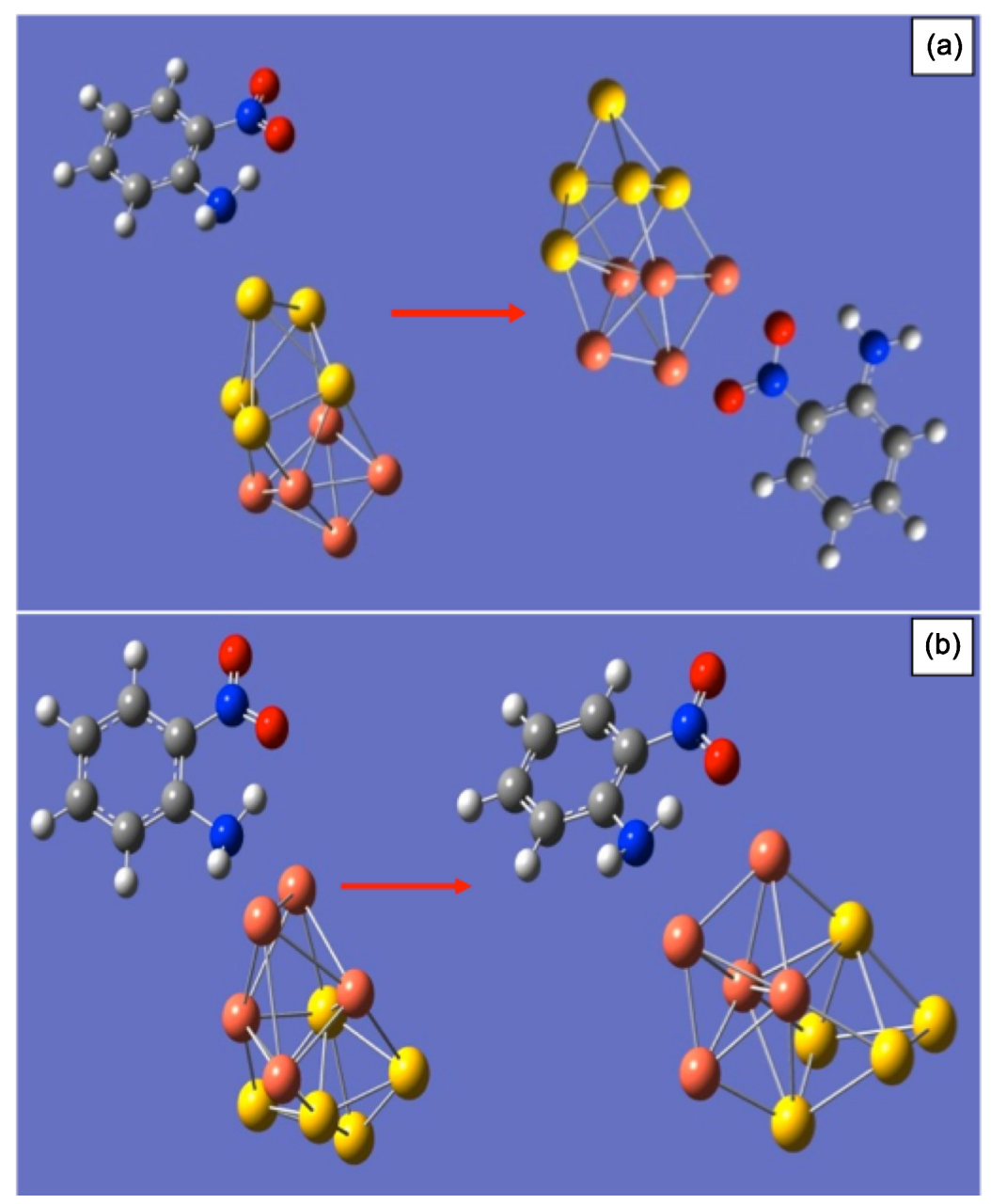

Figure 5. Models of 2-nitroanilne interacting with $\mathrm{Au}-\mathrm{Cu}$ bimetallic substrates. The predicted spectrum based on Model "a" matches with the experimentally derived spectra when the DFT calculation was carried out with the assumption that the $\mathrm{NH}_{2}$ group facing the gold substrate but the molecule would rotate to interact with the copper surface instead. The predicted spectrum and the experimentally derived spectrum are also similar if the DFT calculation is modeled with the $\mathrm{NO}_{2}$ group placed initially nearest to the copper; in which case the molecule would remain in place with the $\mathrm{NO}_{2}$ interacting with the copper substrate. The calculation for Model " $b$ " was performed with the $\mathrm{NH}_{2}$ group initially nearest the copper but there was a shift towards the $\mathrm{NO}_{2}$ group such that the copper moiety in the bimetallic cluster is oriented toward the $\mathrm{NO}_{2}$ group. The predicted spectra for Model " $b$ " contradict the experimentally derived spectra. 


\section{Conclusion}

Regardless of whether SERS analysis was performed using the colloidal nanospheres (Figure 2), nanostars, or the Klarite ${ }^{\mathrm{TM}}$ solid surface (Figure A1 in Appendix A), the spectrum of each nitroaniline isomer can be easily distinguished from one another. In this study, the gold colloidal nanospheres and Klarite ${ }^{\mathrm{TM}}$ gave about a 10-fold signal enhancement compared to the nanostars for the same analyte. The signal enhancement is also analyte dependent. The overall SERS enhancement for gold substrates from strongest to weakest is aniline $>$ 2-nitroaniline $>3$-nitroaniline $>4$-nitroaniline $>$ nitrobenzene. The DFT modeling shows that charge-transfer is an important contributing factor for SERS signal enhancement and the relative strengths of SERS enhancement can be predicted or explained by the HOMO-LUMO energy gaps and Mulliken charges for aniline, nitroaniline isomers, and nitrobenzene. Other contributing factors are the polarizabilities of the electric field produced by the surface plasmon and the inherent molecular dipole movements. In the case of the nitroaniline isomers, there is also a preference for the gold to interact with the $\mathrm{NO}_{2}$ group over the $\mathrm{NH}_{2}$ group. Aniline, 2-nitroaniline, 3-nitroaniline and 4-nitroaniline have a preference for the copper substrate when both gold and copper or $\mathrm{Au}-\mathrm{Cu}$ mixed substrates were used. The DFT study found that the $\mathrm{NO}_{2}$ group in 2-nitroaniline has a very strong preference and affinity for the copper in the $\mathrm{Au}-\mathrm{Cu}$ bimetallic cluster.

\section{Acknowledgements}

The authors would like to thank Professor Ngee Sing Chong at Middle Tennessee State University, for helpful discussion and data interpretation.

\section{References}

[1] Haynes, C.L., McFarland, A.D. and Van Duyne, R.P. (2005) Surface-Enhanced Raman Spectroscopy. Analytical Chemistry, 77, 338A-346A. http://pubs.acs.org/doi/pdf/10.1021/ac053456d

[2] Campion, A. and Kambhampati, P. (1998) Surface-Enhanced Raman Scattering. Chemical Society Reviews, 27, 241-250. https://doi.org/10.1039/a827241z

[3] Wu, D., Zhao, L., Liu, X., Huang, R., Huang, Y., Ren, B. and Tian, Z. (2011) Photon-Driven Charge Transfer and Photocatalysis of $p$-Aminothiophenol in Metal Nanogaps: A DFT Study of SERS. Chemical Communications, 47, 2520-2522. https://doi.org/10.1039/c0cc05302c

[4] Chiş, V., Venter, M.M., Leopold, N. and Cozar, O. (2008) Raman, Surface-Enhanced Raman Scattering and DFT Study of Para-Nitro-Aniline. Vibrational Spectroscopy, 48, 210-214. https://doi.org/10.1016/j.vibspec.2008.01.001

[5] Ma, W. and Fang, Y. (2006) Experimental (SERS) and Theoretical (DFT) Studies on the Adsorption of $p$-, $m$-, and $o$-Nitroaniline on Gold Nanoparticles. Journal of Colloid and Interface Science, 303, 1-8. https://doi.org/10.1016/j.jcis.2006.05.001

[6] Tanaka, T., Nakajima, A., Watanabe, A., Ohno, T. and Ozaki, Y. (2003) Surface-Enhanced Raman Scattering Spectroscopy and Density Functional Theory Calculation Studies on Adsorption of $o^{-}, m^{-}$, and $p$-Nitroaniline on Silver and Gold 
Colloid. Journal of Molecular Structure, 661-662, 437-449.

https://doi.org/10.1016/j.molstruc.2003.09.006

[7] Esenturk, E.N. and Walker, A.R.H. (2009) Surface-Enhanced Raman Scattering Spectroscopy via Gold Nanostars. Journal of Raman Spectroscopy, 40, 86-91.

https://doi.org/10.1002/jrs.2084

[8] Morton, S.M. and Jensen, L. (2009) Understanding the Molecule-Surface Chemical Coupling in SERS. Journal of the American Chemical Society, 131, 4090-4098. https://doi.org/10.1021/ja809143c

[9] Davies, R.A., Chong, N.S. and Ooi, B.G. (2013) Chemical Enhancement of the Surface Enhanced Raman Scattering Signals of Anilines via Their Ortho-Substituents. Optics and Photonics Journal, 3, 13-23. https://doi.org/10.4236/opj.2013.35A003

[10] Chong, N.S., Donthula, K., Davies, R.A., Ilsley, W.H. and Ooi, B.G. (2015) Significance of Chemical Enhancement Effects in Surface-Enhanced Raman Scattering (SERS) Signals of Aniline and Aminobiphenyl Isomers. Vibrational Spectroscopy, 81, 22-31. https://doi.org/10.1016/j.vibspec.2015.09.002

[11] Campion, A., Ivanecky III, J.E., Child, C.M. and Foster, M. (1995) On the Mechanism of Chemical Enhancement in Surface-Enhanced Raman Scattering. Journal of the American Chemical Society, 117, 11807-11808. https://doi.org/10.1021/ja00152a024

[12] Lombardi, J.R., Birke, R.L., Lu, T. and Xu, J. (1986) Charge-Transfer Theory of Surface Enhanced Raman Spectroscopy: Herzberg-Teller Contributions. The Journal of Chemical Physics, 84, 4174-4180. https://doi.org/10.1063/1.450037

[13] Lombardi, J.R. and Birke, R.L. (2008) A Unified Approach to Surface-Enhanced Raman Spectroscopy. The Journal of Physical Chemistry C, 112, 5605-5617. https://doi.org/10.1021/jp800167v

[14] Chong, N.S., Smith, K.A., Setti, S. and Ooi, B.G. (2013) Application of Gold and Silver Colloidal Nanoparticles for the Surface-Enhanced Raman Spectrometric analysis of Melamine and 4-Aminobiphenyl. International Journal of Environmental Technology and Management, 16, 3-20. https://doi.org/10.1504/IJETM.2013.050681

[15] Fleger, Y., Mastai, Y., Rosenbluh, M. and Dressler, D.H. (2009) SERS as a Probe for Adsorbate Orientation on Silver Nanoclusters. Journal of Raman Spectroscopy, 40, 1572-1577. https://doi.org/10.1002/jrs.2300

[16] Dressler, D.H., Mastai, Y., Rosenbluh, M. and Fleger, Y. (2009) Surface-Enhanced Raman Spectroscopy as a Probe for Orientation of Pyridine Compounds on Colloidal Surfaces. Journal of Molecular Structure, 935, 92-96.

https://doi.org/10.1016/j.molstruc.2009.06.042

[17] Dendisová, M., Havránek, L., Onč́k, M. and Matejkka, P. (2013) In Situ SERS Study of Azobenzene Derivative Formation from 4-Aminobenzenethiol on Gold, Silver, and Copper Nanostructured Surfaces: What Is the Role of Applied Potential and Used Metal? The Journal of Physical Chemistry C, 117, 21245-21253.

https://pubs.acs.org/doi/abs/10.1021/jp4040985

[18] Wu, D., Liu, X., Huang, Y., Ren, B., Xu, X. and Tian, Z. (2009) Surface Catalytic Coupling Reaction of $p$-Mercaptoaniline Linking to Silver Nanostructures Responsible for Abnormal SERS Enhancement: A DFT Study. The Journal of Physical Chemistry C, 113, 18212-18222. https://doi.org/10.1021/jp9050929

[19] Wu, D., Liu, X., Duan, S., Xu, X., Ren, B., Lin, S. and Tian, Z. (2008) Chemical Enhancement Effects in SERS Spectra: A Quantum Chemical Study of Pyridine Interacting with Copper, Silver, Gold and Platinum Metals. The Journal of Physical 
Chemistry C, 112, 4195-4204. https://doi.org/10.1021/jp0760962

[20] Xie, J.P., Lee, J.Y. and Wang, D.I.C. (2007) Seedless, Surfactantless, High-Yield Synthesis of Branched Gold Nanocrystals in HEPES Buffer Solution. Chemistry of Materials, 19, 2823-2830. https://doi.org/10.1021/cm0700100

[21] Lee, K.Y., Hwang, J., Lee, Y.W., Kim, J., and Han, J.S. (2007) One-Step Synthesis of gold Nanoparticles using Azacryptand and Their Applications in SERS and Catalysis. Journal of Colloid and Interface Science, 316, 476-481. https://doi.org/10.1016/j.jcis.2007.07.076

[22] Shao, Y., Molnar, L.F., Jung, Y., Kussmann, J., Ochsenfeld, C., Brown, S.T., Gilbert, A.T.B., Slipchenko, L.V., Levchenko, S.V., O’Neill, D.P., DiStasio, R.A., Lochan, R.C., Wang, T., Beran, G.J.O., Besley, N.A., Herbert, J.M., Lin, C.Y., Van Voorhis, T., Chien, S.H., Sodt, A., Steele, R.P., Rassolov, V.A., Maslen, P.E., Korambath, P.P., Adamson, R.D., Austin, B., Baker, J., Byrd, E.F.C., Dachsel, H., Doerksen, R.J., Dreuw, A., Dunietz, B.D., Dutoi, A.D., Furlani, T.R., Gwaltney, S.R., Heyden, A., Hirata, S., Hsu, C.-P., Kedziora, G., Khalliulin, R.Z., Klunzinger, P., Lee, A.M., Lee, M.S., Liang, W.Z., Lotan, I., Nair, N., Peters, B., Proynov, E.I., Pieniazek, P.A., Rhee, Y.M., Ritchie, J., Rosta, E., Sherrill, C.D., Simmonett, A.C., Subotnik, J.E., Woodcock III, H.L., Zhang, W., Bell, A.T., Chakraborty, A.K., Chipman, D.M., Keil, F.J., Warshel, A., Hehre, W.J., Schaefer, H.F., Kong, J., Krylov, A.I., Gill, P.M.W. and Head-Gordon, M. (2006) Advances in Methods and Algorithms in a Modern Quantum Chemistry Program Package. Physical Chemistry Chemical Physics, 8, 3172-3191. https://doi.org/10.1039/B517914A

[23] Frisch, M.J., Trucks, G.W., Schlegel, H.B., Scuseria, G.E., Robb, M.A., Cheeseman, J.R., Scalmani, G., Barone, V., Petersson, G.A., Nakatsuji, H., Li, X., Caricato, M., Marenich, A., Bloino, J., Janesko, B.G., Gomperts, R., Mennucci, B., Hratchian, H.P., Ortiz, J.V., Izmaylov, A.F., Sonnenberg, J.L., Williams-Young, D., Ding, F., Lipparini, F., Egidi, F., Goings, J., Peng, B., Petrone, A., Henderson, T., Ranasinghe, D., Zakrzewski, V.G., Gao, J., Rega, N., Zheng, G., Liang, W., Hada, M., Ehara, M., Toyota, K., Fukuda, R., Hasegawa, J., Ishida, M., Nakajima, T., Honda, Y., Kitao, O., Nakai, H., Vreven, T., Throssell, K., Montgomery, J.A., Peralta, J.E., Ogliaro, F., Bearpark, M., Heyd, J.J., Brothers, E., Kudin, K.N., Staroverov, V.N., Keith, T., Kobayashi, R., Normand, J., Raghavachari, K., Rendell, A., Burant, J.C., Iyengar, S.S., Tomasi, J., Cossi, M., Millam, J.M., Klene, M., Adamo, C., Cammi, R., Ochterski, J.W., Martin, R.L., Morokuma, K., Farkas, O., Foresman, J.B. and Fox, D.J. (2016) Gaussian 09, Revision C.01. Gaussian, Inc., Wallingford, CT.

[24] Becke, A.D. (1993) Density-Functional Thermochemistry. III. The Role of Exact Exchange. The Journal of Chemical Physics, 98, 5648-5652. https://doi.org/10.1063/1.464913

[25] Krishnan, R., Binkley, J.S., Seeger, R. and Pople, J.A. (1980) Self-Consistent Molecular Orbital Methods. XX. A Basis Set for Correlated Wave Functions. The Journal of Chemical Physics, 72, 650-654. https://doi.org/10.1063/1.438955

[26] Wadt, W.R. and Hay, P.J. (1985) Ab Initio Effective Core Potentials for Molecular Calculations. Potentials for Main Group Elements Sodium to Bismuth. The Journal of Chemical Physics, 82, 284-298. https://doi.org/10.1063/1.448800

[27] Hay, P.J. and Wadt, W.R. (1985) Ab Initio Effective Core Potentials for Molecular Calculations. Potentials for Potassium to Gold Including the Outermost Core Orbitals. The Journal of Chemical Physics, 82, 299-310. https://doi.org/10.1063/1.448975

[28] Mulliken, R.S. (1955) Electronic Population Analysis on LCAO-MO Molecular Wave Functions. The Journal of Chemical Physics, 23, 1833-1840. 
https://doi.org/10.1063/1.1740588

[29] Nie, S. and Emory, S.R. (1997) Probing Single Molecules and Single Nanoparticles by Surface-Enhanced Raman Scattering. Science, 275, 1102-1106. https://doi.org/10.1126/science.275.5303.1102

[30] Kneipp, K., Kneipp, H., Itzkan, I., Dasari, R.R. and Feld, M.S. (1999) Ultrasensitive Chemical Analysis by Raman Spectroscopy. Chemical Reviews, 99, 2957-2975. https://doi.org/10.1021/cr980133r

[31] Kwon, K., Lee, K.Y., Lee, Y.W., Kim, M., Heo, J., Ahn, S.J. and Han, S.W. (2007) Controlled Synthesis of Icosahedral Gold Nanoparticles and Their Surface-Enhanced Raman Scattering Property. The Journal of Physical Chemistry C, 111, 1161-1165. https://doi.org/10.1021/jp064317i

[32] Le Ru, E.C., Blackie, E., Meyer, M. and Etchegoin, P.G. (2007) Surface Enhanced Raman Scattering Enhancement Factors: A Comprehensive Study. The Journal of Physical Chemistry C, 111, 13794-13803. https://doi.org/10.1021/jp0687908

[33] Zhao, L.-B., Huang, R., Bai, M.-X., Wu, D.-Y. and Tian, Z.-Q. (2011) Effect of Aromatic Amine-Metal Interaction on Surface Vibrational Raman Spectroscopy of Adsorbed Molecules Investigated by Density Functional Theory. The Journal of Physical Chemistry C, 115, 4174-4183. https://doi.org/10.1021/jp1117135

[34] Palafox, M.A., Nunez, J.L. and Gil, M. (2002) Accurate Scaling of Vibrational Spectra of Aniline and Several Derivatives. Journal of Molecular Structure: THEOCHEM, 593, 101-131. https://doi.org/10.1016/S0166-1280(02)00319-6

[35] Vaschetto, M.E., Retamal, B.A. and Monkman, A.P. (1999) Density Functional Studies of Aniline and Substituted Anilines. Journal of Molecular Structure. THEOCHEM, 468, 209-221. https://doi.org/10.1016/S0166-1280(98)00624-1

[36] Xi, W., Shrestha, B.K. and Haes, A.J. (2018) Promoting Intra- and Intermolecular Interactions in Surface-Enhanced Raman Scattering. Analytical Chemistry, 90, 128-143. https://doi.org/10.1021/acs.analchem.7b04225

[37] Moskovits, M. (1978) Surface Roughness and the Enhanced Intensity of Raman Scattering by Molecules Adsorbed on Metals. The Journal of Chemical Physics, 69, 4159-4161. https://doi.org/10.1063/1.437095

[38] Moskovits, M. (1985) Surface-Enhanced Spectroscopy. Reviews of Modern Physics, 57, 783-826. https://doi.org/10.1103/RevModPhys.57.783

[39] Aihara, N., Torigoe, K. and Esumi, K. (1998) Preparation and Characterization of Gold and Silver Nanoparticles in Layered Laponite Suspension. Langmuir, 14, 4945-4949. https://doi.org/10.1021/la980370p

[40] Han, S.W., Kim, Y. and Kim, K. (1998) Dodecanethiol-Derivatized Au/Ag Bimetallic Nanoparticles: TEM, UV/VIS, XPS, and FTIR Analysis. Journal of Colloid and Interface Science, 208, 272-278. https://doi.org/10.1006/jcis.1998.5812

[41] Freeman, R.G., Hommer, M.B., Grabar, K.C., Jackson, M.A. and Natan, M.J. (1996) Ag-Clad Au Nanoparticles: Novel Aggregation, Optical, and Surface-Enhanced Raman Scattering Properties. The Journal of Physical Chemistry, 100, 718-724. https://doi.org/10.1021/jp951379s

[42] Rivas, L., Sanchez-Cortes, S., Garcia-Ramos, J.V. and Morcillo, G. (2000) Mixed Silver/Gold Colloids: A Study of Their Formation, Morphology, and Surface-Enhanced Raman Activity. Langmuir, 16, 9722-9728. https://doi.org/10.1021/la000557s

[43] Wang, Y., Chen, H., Dong, S. and Wang, E. (2006) Surface-Enhanced Raman Scattering of Silver-Gold Bimetallic Nanostructures with Hollow Interiors. The Journal 
of Chemical Physics, 125, 1-7. https://doi.org/10.1063/1.2216694

[44] Wang, C., Fang, J., Jin, Y. and Cheng, M. (2011) Fabrication and Surface-Enhanced Raman Scattering (SERS) of Ag/Au Bimetallic Films on Si Substrates. Applied Surface Science, 258, 1144-1148. https://doi.org/10.1016/j.apsusc.2011.09.052 


\section{Appendix A. Supplementary Data}

Supplementary data associated with this manuscript are in this section.

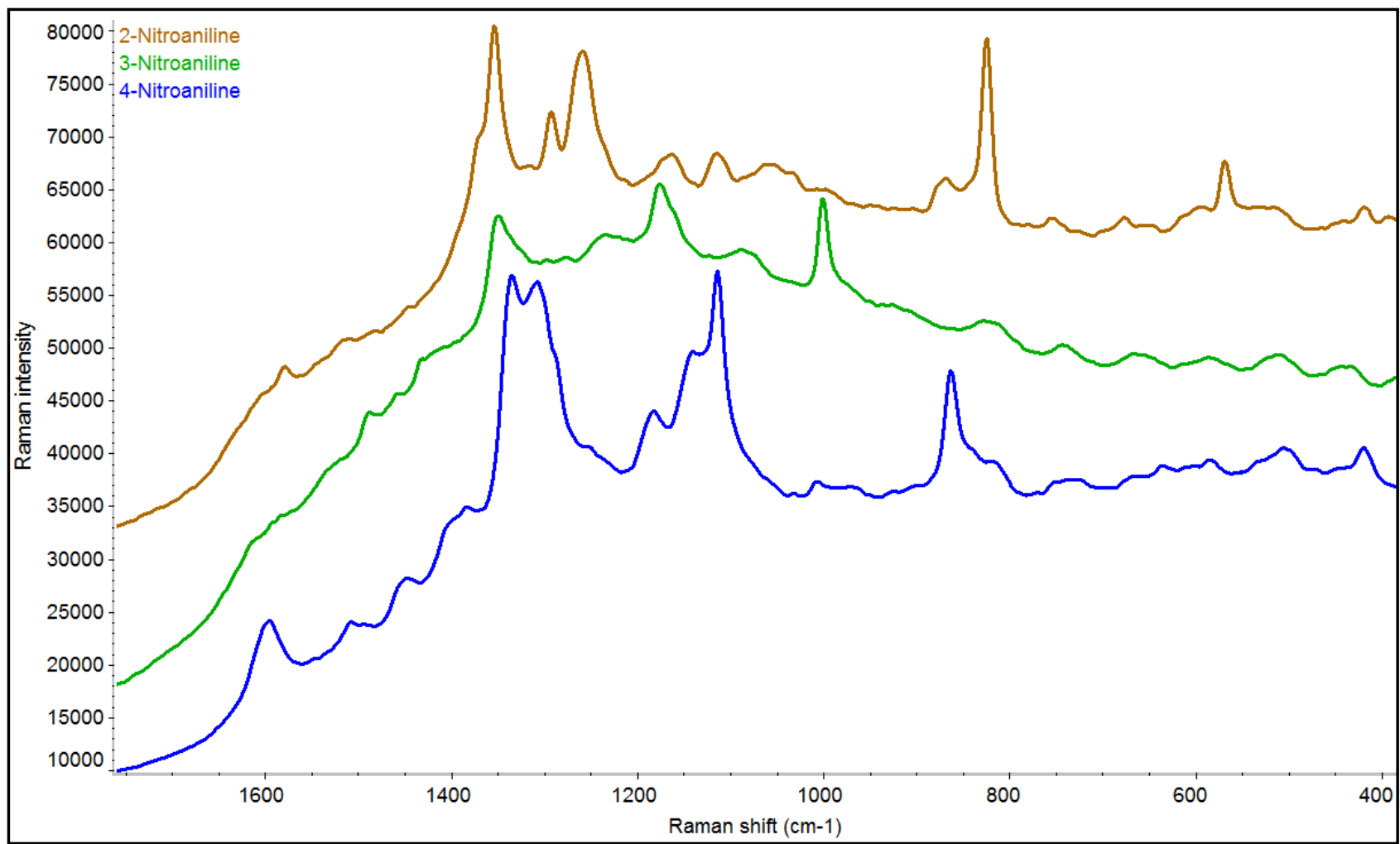

Each spectrum was collected using $1 \mu \mathrm{L}$ of analyte solution on a Klarite ${ }^{\mathrm{TM}}$ gold chip. The concentration of the analytes was as follows: 1100 ppm 2-nitroaniline, 833.3 ppm 3-nitroaniline and 800 ppm 4-nitroaniline. The Raman spectra shown in full scale with offset mode were collected using the same laser power settings and 30 seconds of integration time.

Figure A1. Klarite ${ }^{\mathrm{TM}}$ substrate with different isomers of nitroaniline. 
Table A1. Vibrational modes and corresponding wavenumbers of SERS spectral peaks.

\begin{tabular}{|c|c|c|c|}
\hline \multirow{2}{*}{ Aromatic Amines } & \multirow{2}{*}{ Vibrational Mode Assignment } & \multicolumn{2}{|c|}{ SERS Spectra Wavenumber $\left(\mathrm{cm}^{-1}\right)$} \\
\hline & & Theo. & Expt. \\
\hline \multirow{8}{*}{ Aniline } & $\mathrm{NH}_{2}$ wag & 1046 & 996 \\
\hline & $\mathrm{C}_{2} \mathrm{NC}_{6} \mathrm{~s}$-str & 812 & 824 \\
\hline & $\mathrm{R}$ br $\left\{\mathrm{NH}_{2}\right.$ wag $\}$ & 1015 & 960 \\
\hline & $\mathrm{RC}_{2,3} \mathrm{C}_{5,6} \mathrm{H}$ ip s-sc $\left\{\mathrm{NH}_{2}\right.$ wag $\} /$ & $1048 / 1185 / 1201$ & $1025 / 1144 / 1172$ \\
\hline & $\mathrm{RC}_{3,4} \mathrm{C}_{5,6} \mathrm{H}$ ip s-sc/ $\mathrm{RC}_{2,3} \mathrm{C}_{5,6} \mathrm{H}$ ip s-sc & & \\
\hline & 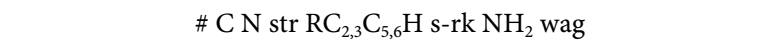 & 1235 & 1214 \\
\hline & $\mathrm{RC}_{1,2} \mathrm{C}_{4,5} \mathrm{H}$ s-str/ & $1643 / 1642 / 1651$ & $1558 / 1571 / 1592$ \\
\hline & $\mathrm{RC}_{2,3} \mathrm{C}_{5,6} \mathrm{H}$ s-str $\mathrm{NH}_{2} \mathrm{sc} / \mathrm{NH}_{2} \mathrm{sc}$ & & \\
\hline \multirow{9}{*}{ 2-Nitroaniline } & $\mathrm{NH}_{2}$ wag & 263 & $\mathrm{OSR}^{*}$ \\
\hline & $\mathrm{NO}_{2} \mathrm{sc} \mathrm{R}$ br C NH$H_{2} \mathrm{str}$ & 836 & 817 \\
\hline & $\begin{array}{c}\mathrm{C}_{3,4} \mathrm{C}_{5,6} \mathrm{H} \text { ip s-sc } \mathrm{NH}_{2} \text { rk/ } \mathrm{C}_{3,4} \mathrm{C}_{5,6} \mathrm{H} \text { ip as-sc } \mathrm{NH}_{2} \text { rk/ } \mathrm{C}_{3,4} \mathrm{C}_{5,6} \mathrm{H} \text { ip s-sc } \\
\mathrm{NH}_{2} \text { rk }\end{array}$ & $1070 / 1186 / 1195$ & $1048 / 1179 / 1195$ \\
\hline & $\mathrm{C} \mathrm{NO}_{2}$ str $\mathrm{C} \mathrm{NH}_{2}$ str $\mathrm{RC}_{2} \mathrm{C}_{3}$ str $\mathrm{NH}_{2} \mathrm{sc}$ & 1270 & 1255 \\
\hline & $\mathrm{RC}_{3,4} \mathrm{C}_{5,6} \mathrm{H}$ ip s-rk $\mathrm{NH}_{2}$ rk & 1309 & 1285 \\
\hline & $\mathrm{RC}_{3,4} \mathrm{C}_{5,6} \mathrm{H}$ ip s-rk $\mathrm{NH}_{2}$ rk C NO${ }_{2}$ str & 1359 & 1349 \\
\hline & $\mathrm{RC}_{1,2} \mathrm{C}_{3,4} \mathrm{C}_{5,6}$ s-str $\mathrm{NH}_{2} \mathrm{rk}$ & 1397 & 1368 \\
\hline & $\mathrm{RC}_{1,2} \mathrm{C}_{4,5} \mathrm{~s}-\mathrm{str} \mathrm{NH}_{2} \mathrm{sc} / \mathrm{NH}_{2} \mathrm{sc} /$ & $1600 / 1624 / 1662$ & $1521 / 1608 / 1571$ \\
\hline & $\mathrm{RC}_{2,3} \mathrm{C}_{5,6} \mathrm{~s}$-str $\mathrm{C} \mathrm{NH}_{2} \operatorname{str} \mathrm{NH}_{2} \mathrm{sc}$ & & \\
\hline \multirow{7}{*}{ 3-Nitroaniline } & $\mathrm{NH}_{2}$ wag & 464 & 483 \\
\hline & $\mathrm{NO}_{2}$ sc R br C NH$H_{2}$ str & 839 & 808 \\
\hline & $\mathrm{RC}_{2,4,6} \operatorname{str}(\mathrm{R}$ br $)$ & 1009 & 996 \\
\hline & $\begin{array}{c}\mathrm{NH}_{2} \mathrm{rk} \mathrm{RC}_{4} \mathrm{C}_{6} \mathrm{H} \mathrm{sc} / \mathrm{NH}_{2} \mathrm{rk} \mathrm{RC}_{2,4,6} \mathrm{H} \text { as-sc/ } \\
\mathrm{RC}_{4,5,6} \mathrm{H} \text { as-sc }\end{array}$ & $1077 / 1128 / 1194$ & $1043 / 1162 / 1216$ \\
\hline & $\mathrm{C} \mathrm{NH}_{2}$ str $\mathrm{RC}_{2} \mathrm{C}_{4} \mathrm{H}$ ip s-rk & 1299 & 1270 \\
\hline & $\# \mathrm{C} \mathrm{NO}_{2} \operatorname{str}\left\{\mathrm{RC}_{2,4,6} \mathrm{H}\right.$ ip s-rk C NH${ }_{2}$ str $\}$ & 1309 & 1345 \\
\hline & $\begin{array}{c}\mathrm{RC}_{1,2} \mathrm{C}_{4,5} \mathrm{~s} \text {-str } \mathrm{NH}_{2} \mathrm{rk} / \mathrm{NH}_{2} \mathrm{sc} \mathrm{RC}_{2,3} \mathrm{C}_{5,6} \mathrm{~s} \text {-str/ } \\
\mathrm{NH}_{2} \mathrm{sc} \mathrm{RC}_{2,3} \mathrm{C}_{5,6} \mathrm{~s} \text {-str }\end{array}$ & $1615 / 1669 / 1652$ & $1612 / 1622 / 1646$ \\
\hline \multirow{8}{*}{ 4-Nitroaniline } & $\mathrm{NH}_{2}$ wag & 243 & $\mathrm{OSR}^{*}$ \\
\hline & $\mathrm{NO}_{2} \mathrm{sc} \mathrm{R}$ br & 878 & 859 \\
\hline & $\mathrm{RC}_{2,3} \mathrm{C}_{5,6} \mathrm{H}$ as-sc $\mathrm{NH}_{2}$ rk $/ \mathrm{RC}_{2,3} \mathrm{C}_{5,6} \mathrm{H}$ as-sc $\mathrm{NH}_{2}$ rk/ & $1049 / 1154 / 1207$ & $1045 / 1148 / 1175$ \\
\hline & $\mathrm{RC}_{2,3} \mathrm{C}_{4,5} \mathrm{H}$ ip s-sc & & \\
\hline & $\mathrm{C} \mathrm{NH}_{2}$ str $\mathrm{RC}_{2,3} \mathrm{C}_{5,6} \mathrm{~s}$-rk & 1347 & 1316 \\
\hline & $\# \mathrm{C} \mathrm{NO}_{2} \operatorname{str} \mathrm{C} \mathrm{NH}_{2}$ str $\mathrm{RC}_{2} \mathrm{C}_{6} \mathrm{H} \mathrm{sc}$ & 1303 & 1332 \\
\hline & $\mathrm{RC}_{1,2} \mathrm{C}_{3,4} \mathrm{C}_{5,6} \mathrm{~s}$-str $\mathrm{NH}_{2} \mathrm{rk}$ & 1379 & 1379 \\
\hline & $\begin{array}{c}\mathrm{NO}_{2} \text { as-str } \mathrm{RC}_{1,2} \mathrm{C}_{4,5} \mathrm{~s} \text {-str/ } \mathrm{NH}_{2} \mathrm{sc} \mathrm{RC}_{2,3} \mathrm{C}_{5,6} \mathrm{~s} \text {-str/ } \\
\mathrm{NH}_{2} \mathrm{sc}\end{array}$ & $1617 / 1643 / 1665$ & $1572 / 1596 / 1626$ \\
\hline \multirow{6}{*}{ Nitrobenzene } & $\mathrm{NO}_{2}$ sc $\mathrm{R}$ br C N str & 877 & 860 \\
\hline & $\mathrm{RC}_{2,4,6} \operatorname{str}(\mathrm{R} \mathrm{br})$ & 1017 & 1010 \\
\hline & $\mathrm{RC}_{2,3} \mathrm{C}_{5,6} \mathrm{H}$ ip s-sc $/ \mathrm{RC}_{2,3} \mathrm{C}_{4,5} \mathrm{H}$ as-sc/ & $1042 / 1188 / 1199$ & $1023 / 1151 / 1177$ \\
\hline & $\mathrm{RC}_{2,3} \mathrm{C}_{5,6} \mathrm{H}$ ip s-sc & & \\
\hline & $\# \mathrm{C} \mathrm{NO}_{2}$ str $\mathrm{RC}_{2,3} \mathrm{C}_{5,6} \mathrm{H} \mathrm{s}$-sc & 1305 & 1339 \\
\hline & $\begin{array}{c}\text { \# } \mathrm{NO}_{2} \text { as-str } \mathrm{RC}_{3,4,} \mathrm{C}_{4,5} \text { as str/ } \mathrm{RC}_{2,3} \mathrm{C}_{5,6} \mathrm{~s} \text {-str/ } \\
\mathrm{NO}_{2} \text { as-str } \mathrm{RC}_{1,2} \mathrm{C}_{4,5} \text { s-str }\end{array}$ & $1552 / 1627 / 1643$ & $1547 / 1590 / 1616$ \\
\hline
\end{tabular}

The abbreviations are br: breathing, rk: rock, str: stretch, tw: twist, sc: scissoring, wag: wagging, s: symmetric, as: asymmetric, ip: in-plane and R: ring. \{\} Mode is present only in the SERS spectra. [ ] Mode not present in SERS. \# Predominant mode; $\mathrm{RC}_{2,4,6}$ str also means R br. and OSR*: Outside spectrometer range. 
Table A2. Mulliken charges for analytes, Au clusters and Au-analyte interaction.

\begin{tabular}{|c|c|c|c|c|c|c|c|c|c|c|c|c|c|c|c|}
\hline & $\begin{array}{c}\text { Aniline/ } \\
4 \mathrm{Au}\end{array}$ & $\begin{array}{l}\text { 4Au- } \\
\text { Aniline }\end{array}$ & $\begin{array}{c}\text { Diff. } \\
\text { Aniline }\end{array}$ & 2-NA & $\begin{array}{l}4 \mathrm{Au}- \\
2 \mathrm{NA}\end{array}$ & $\begin{array}{c}\text { Diff. } \\
\text { 2-NA }\end{array}$ & 3-NA & $\begin{array}{l}4 \mathrm{Au}- \\
3 \mathrm{NA}\end{array}$ & $\begin{array}{c}\text { Diff. } \\
\text { 3-NA }\end{array}$ & 4-NA & $\begin{array}{l}4 \mathrm{Au}- \\
4 \mathrm{NA}\end{array}$ & $\begin{array}{l}\text { Diff. } \\
\text { 4-NA }\end{array}$ & $\mathrm{NBz}$ & $\begin{array}{l}4 \mathrm{Au}- \\
\mathrm{NBz}\end{array}$ & $\begin{array}{l}\text { Diff. } \\
\text { NBz }\end{array}$ \\
\hline $\mathrm{H} 1$ & 0.138 & 0.156 & 0.018 & 0.178 & 0.193 & 0.015 & 0.227 & 0.239 & 0.012 & & & & 0.173 & 0.169 & -0.004 \\
\hline $\mathrm{C} 2$ & -0.297 & -0.232 & 0.065 & -0.348 & -0.303 & 0.045 & -0.052 & -0.270 & -0.218 & -0.347 & -0.288 & 0.059 & 0.034 & -0.343 & -0.377 \\
\hline C3 & -0.132 & 0.706 & 0.838 & 0.008 & -0.064 & -0.072 & -0.096 & -0.082 & 0.014 & -0.322 & -0.325 & -0.003 & -0.968 & -0.076 & 0.892 \\
\hline $\mathrm{C} 4$ & -0.144 & -0.210 & -0.066 & 0.005 & -0.018 & -0.023 & -0.183 & -0.094 & 0.089 & -0.024 & -0.336 & -0.312 & -0.602 & -0.093 & 0.509 \\
\hline C5 & -0.144 & -0.210 & -0.066 & -0.303 & -0.340 & -0.037 & -0.183 & -0.205 & -0.022 & -0.025 & 0.254 & 0.279 & -0.602 & -0.138 & 0.464 \\
\hline C6 & -0.080 & -0.260 & -0.180 & 0.003 & 0.087 & 0.084 & -0.178 & -0.158 & 0.020 & -0.027 & 0.050 & 0.077 & 0.624 & -0.278 & -0.902 \\
\hline C7 & -0.077 & -0.259 & -0.182 & -0.006 & 0.063 & 0.069 & -0.056 & 0.120 & 0.176 & -0.027 & -0.065 & -0.038 & 0.624 & 0.176 & -0.448 \\
\hline H8 & 0.158 & 0.180 & 0.022 & 0.243 & 0.248 & 0.005 & & & & 0.239 & 0.253 & 0.014 & 0.181 & 0.202 & 0.021 \\
\hline H9 & 0.159 & 0.180 & 0.021 & 0.165 & 0.171 & 0.006 & 0.187 & 0.197 & 0.010 & 0.239 & 0.240 & 0.001 & 0.181 & 0.204 & 0.023 \\
\hline $\mathrm{H} 10$ & 0.128 & 0.123 & -0.005 & 0.147 & 0.165 & 0.018 & 0.142 & 0.149 & 0.007 & 0.163 & 0.174 & 0.011 & 0.265 & 0.242 & -0.023 \\
\hline H11 & 0.128 & 0.123 & -0.005 & & & & 0.220 & 0.217 & 0.000 & 0.163 & 0.174 & 0.011 & 0.265 & 0.234 & -0.031 \\
\hline N12 & -0.307 & -0.394 & -0.087 & -0.353 & -0.341 & 0.012 & -0.312 & -0.310 & 0.002 & -0.291 & -0.296 & -0.005 & & & \\
\hline H13 & 0.234 & 0.259 & 0.025 & 0.312 & 0.279 & -0.033 & 0.250 & 0.255 & 0.005 & 0.252 & 0.264 & 0.012 & & & \\
\hline H14 & 0.234 & 0.259 & 0.025 & 0.265 & 0.311 & 0.046 & 0.247 & 0.252 & 0.005 & 0.252 & 0.265 & 0.013 & & & \\
\hline N15 & & & & -0.211 & -0.094 & 0.117 & -0.186 & -0.031 & 0.155 & -0.179 & -0.011 & 0.168 & -0.136 & -0.030 & 0.106 \\
\hline O16 & & & & -0.021 & -0.038 & -0.017 & -0.014 & 0.002 & 0.016 & -0.034 & -0.029 & 0.005 & -0.018 & -0.004 & 0.014 \\
\hline $\mathrm{O} 17$ & & & & -0.085 & -0.008 & 0.077 & -0.013 & -0.003 & 0.010 & -0.034 & -0.029 & 0.005 & -0.018 & 0.000 & 0.018 \\
\hline Aul8 & 0.152 & 0.351 & 0.199 & & 0.296 & 0.144 & & 0.319 & 0.167 & & 0.325 & 0.173 & & 0.320 & 0.168 \\
\hline Au19 & 0.152 & -0.149 & -0.301 & & -0.100 & -0.252 & & -0.096 & -0.248 & & -0.104 & -0.256 & & -0.093 & -0.245 \\
\hline $\mathrm{Au} 20$ & -0.152 & -0.312 & -0.160 & & -0.253 & -0.101 & & -0.250 & -0.098 & & -0.259 & -0.107 & & -0.247 & -0.095 \\
\hline $\mathrm{Au} 21$ & -0.152 & -0.312 & -0.160 & & -0.253 & -0.101 & & -0.249 & -0.097 & & -0.258 & -0.106 & & -0.245 & -0.093 \\
\hline Anet & -0.002 & 0.421 & 0.423 & -0.001 & 0.311 & 0.312 & 0.000 & 0.278 & 0.281 & -0.002 & 0.295 & 0.297 & 0.003 & 0.265 & 0.262 \\
\hline Clnet & 0.000 & -0.422 & -0.422 & & -0.310 & -0.310 & & -0.276 & -0.276 & & -0.296 & -0.296 & & -0.265 & -0.265 \\
\hline
\end{tabular}

The gold cluster consists of $4 \mathrm{Au}$ atoms. The nitroaniline isomers 2-nitroaniline, 3-nitroaniline and 4-nitroaniline are abbreviated as 2-NA, 3-NA and 4-NA respectively. Nitrobenzene is abbreviated as NBz. The charge differences (Diff.) between the Au-analyte and their corresponding analyte are listed in the table. Anet refers to the net charge on the analyte and Clnet refers to the net charge on the metal clusters. C3 is the carbon that is bonded to the nitrogen of the amino group of aniline and nitroanilines. In nitrobenzene, carbon $\mathrm{C} 3$ is bonded to the nitrogen of the nitro group. The carbon $\mathrm{C} 7, \mathrm{C} 4$ and $\mathrm{C} 2$ are bonded to the nitrogen of nitro group of 2-nitroaniline, 3-nitroaniline and 4-nitroaniline, respectively. N12 is the nitrogen of the amino group and N15 is the nitrogen of the nitro group. 
Table A3. Mulliken charges for analytes, $\mathrm{AuCu}$ clusters and $\mathrm{AuCu}$-analyte interaction.

\begin{tabular}{|c|c|c|c|c|c|c|c|c|c|c|c|c|c|c|c|}
\hline & $\begin{array}{l}\text { Aniline/ } \\
5 \mathrm{Au} 5 \mathrm{Cu}\end{array}$ & 5Au5Cu-Aniline & $\begin{array}{l}\text { Diff. } \\
\text { Aniline }\end{array}$ & 2-NA & $\begin{array}{c}5 \mathrm{Au} 5 \mathrm{Cu} \\
-2 \mathrm{NA}\end{array}$ & $\begin{array}{l}\text { Diff. } \\
\text { 2-NA }\end{array}$ & $3-N A$ & $\begin{array}{c}5 \mathrm{Au} 5 \mathrm{Cu} \\
-3 \mathrm{NA}\end{array}$ & $\begin{array}{l}\text { Diff. } \\
\text { 3-NA }\end{array}$ & $4-\mathrm{NA}$ & $\begin{array}{c}5 \mathrm{Au} 5 \mathrm{Cu} \\
-4 \mathrm{NA}\end{array}$ & $\begin{array}{c}\text { Diff. } \\
\text { 4-NA }\end{array}$ & $\mathrm{NBz}$ & $\begin{array}{c}5 \mathrm{Au} 5 \mathrm{Cu} \\
-\mathrm{NBz}\end{array}$ & $\begin{array}{l}\text { Diff. } \\
\text { NBz }\end{array}$ \\
\hline $\mathrm{H} 1$ & 0.138 & 0.190 & 0.052 & 0.178 & 0.192 & 0.014 & 0.227 & 0.257 & 0.030 & & & & 0.173 & 0.163 & -0.010 \\
\hline $\mathrm{C} 2$ & -0.297 & -0.310 & -0.013 & -0.348 & -0.317 & 0.031 & -0.052 & -0.084 & -0.032 & -0.347 & -0.415 & -0.068 & 0.034 & -0.306 & -0.340 \\
\hline $\mathrm{C} 3$ & -0.132 & 0.536 & 0.668 & 0.008 & 0.106 & 0.098 & -0.096 & 0.488 & 0.584 & -0.322 & 0.533 & 0.855 & -0.968 & -0.019 & 0.949 \\
\hline $\mathrm{C} 4$ & -0.144 & -0.316 & -0.172 & 0.005 & -0.089 & -0.094 & -0.183 & -0.184 & -0.001 & -0.024 & -0.191 & -0.167 & -0.602 & -0.157 & 0.446 \\
\hline C5 & -0.144 & -0.232 & -0.088 & -0.303 & -0.332 & -0.029 & -0.183 & -0.335 & -0.152 & -0.025 & 0.010 & 0.035 & -0.602 & -0.124 & 0.478 \\
\hline C6 & -0.080 & -0.242 & -0.162 & 0.003 & -0.089 & -0.092 & -0.178 & -0.564 & -0.386 & -0.027 & -0.416 & -0.389 & 0.624 & 0.011 & -0.613 \\
\hline C7 & -0.077 & -0.627 & -0.550 & -0.006 & 0.103 & 0.109 & -0.056 & -0.510 & -0.454 & -0.027 & -0.634 & -0.607 & 0.624 & -0.004 & -0.628 \\
\hline H8 & 0.158 & 0.235 & 0.077 & 0.243 & 0.220 & -0.023 & & & & 0.239 & 0.318 & 0.079 & 0.181 & 0.188 & 0.007 \\
\hline H9 & 0.159 & 0.197 & 0.038 & 0.165 & 0.170 & 0.005 & 0.187 & 0.219 & 0.032 & 0.239 & 0.272 & 0.033 & 0.181 & 0.197 & 0.016 \\
\hline $\mathrm{H} 10$ & 0.128 & 0.146 & 0.018 & 0.147 & 0.159 & 0.012 & 0.142 & 0.154 & 0.012 & 0.163 & 0.172 & 0.009 & 0.265 & 0.067 & -0.198 \\
\hline H11 & 0.128 & 0.267 & 0.139 & & & 0.000 & 0.220 & 0.296 & 0.076 & 0.163 & 0.330 & 0.167 & 0.265 & 0.230 & -0.035 \\
\hline N12 & -0.307 & -0.327 & -0.020 & -0.353 & -0.356 & -0.003 & -0.312 & -0.304 & 0.008 & -0.291 & -0.330 & -0.039 & & & \\
\hline $\mathrm{H} 13$ & 0.234 & 0.257 & 0.023 & 0.312 & 0.328 & 0.016 & 0.250 & 0.268 & 0.018 & 0.252 & 0.270 & 0.018 & & & \\
\hline H14 & 0.234 & 0.308 & 0.074 & 0.265 & 0.282 & 0.017 & 0.247 & 0.322 & 0.075 & 0.252 & 0.319 & 0.067 & & & \\
\hline N15 & & & & -0.211 & -0.298 & -0.087 & -0.186 & -0.181 & 0.005 & -0.179 & -0.184 & -0.005 & -0.136 & -0.185 & -0.049 \\
\hline $\mathrm{O} 16$ & & & & -0.021 & -0.041 & -0.020 & -0.014 & 0.032 & 0.046 & -0.034 & 0.002 & 0.036 & -0.018 & 0.049 & 0.067 \\
\hline $\mathrm{O} 17$ & & & & -0.085 & -0.076 & 0.009 & -0.013 & 0.023 & 0.036 & -0.034 & 0.011 & 0.045 & -0.018 & -0.007 & 0.011 \\
\hline Au18 & -0.414 & -0.665 & -0.251 & & -0.535 & -0.121 & & -0.667 & -0.253 & & -0.658 & -0.244 & & -0.119 & 0.295 \\
\hline Au19 & -0.512 & 0.055 & 0.567 & & -0.227 & 0.285 & & 0.136 & 0.648 & & 0.114 & 0.626 & & 0.028 & 0.540 \\
\hline $\mathrm{Au} 20$ & -0.372 & -0.651 & -0.279 & & -0.520 & -0.148 & & -0.660 & -0.288 & & -0.635 & -0.263 & & -0.338 & 0.034 \\
\hline $\mathrm{Au} 21$ & -0.372 & -0.639 & -0.267 & & -0.484 & -0.112 & & -0.657 & -0.285 & & -0.656 & -0.284 & & -0.476 & -0.104 \\
\hline $\mathrm{Au} 22$ & -0.049 & -0.604 & -0.555 & & -0.538 & -0.489 & & -0.600 & -0.551 & & -0.606 & -0.557 & & -0.579 & -0.530 \\
\hline $\mathrm{Cu} 23$ & 0.648 & 0.377 & -0.271 & & 0.765 & 0.117 & & 0.528 & -0.120 & & 0.516 & -0.132 & & 0.631 & -0.017 \\
\hline $\mathrm{Cu} 24$ & 0.084 & 0.978 & 0.894 & & 0.694 & 0.610 & & 1.315 & 1.231 & & 0.984 & 0.900 & & 0.059 & -0.025 \\
\hline $\mathrm{Cu} 25$ & 0.150 & 0.424 & 0.274 & & 0.256 & 0.106 & & 0.452 & 0.302 & & 0.438 & 0.288 & & 0.171 & 0.021 \\
\hline $\mathrm{Cu} 26$ & 0.648 & 0.550 & -0.098 & & 0.616 & -0.032 & & 0.267 & -0.381 & & 0.377 & -0.271 & & 0.372 & -0.276 \\
\hline $\mathrm{Cu} 27$ & 0.190 & 0.090 & -0.100 & & 0.009 & -0.181 & & -0.009 & -0.199 & & 0.059 & -0.131 & & 0.148 & -0.042 \\
\hline Anet & -0.002 & 0.082 & 0.084 & -0.001 & -0.038 & -0.037 & 0.000 & -0.104 & -0.104 & -0.002 & 0.067 & 0.069 & 0.002 & 0.104 & 0.101 \\
\hline Clnet & 0.000 & -0.085 & -0.085 & & 0.036 & 0.036 & & 0.105 & 0.105 & & -0.067 & -0.067 & & -0.103 & -0.103 \\
\hline
\end{tabular}

The gold cluster consists of $5 \mathrm{Au}$ and $5 \mathrm{Cu}$ atoms. The nitroaniline isomers 2-nitroaniline, 3-nitroaniline and 4-nitroaniline are abbreviated as 2-NA, 3-NA and 4-NA respectively. Nitrobenzene is abbreviated as NBz. The charge differences (Diff.) between the $5 \mathrm{AuCu}$-analyte and their corresponding analyte are listed in the table. Anet refers to the net charge on the analyte and Clnet refers to the net charge on the metal clusters. 